\title{
Global gene expression profiles of canine macrophages and canine mammary cancer cells grown as a co-culture in vitro
}

\author{
Magdalena Król ${ }^{1 *}$, Karol M Pawłowski², Kinga Majchrzak¹, Małgorzata Gajewska', Alicja Majewska and
} Tomasz Motyl ${ }^{1}$

\begin{abstract}
Background: Solid tumours comprise various cells, including cancer cells, resident stromal cells, migratory haemopoietic cells and other. These cells regulate tumour growth and metastasis. Macrophages constitute probably the most important element of all interactions within the tumour microenvironment. However, the molecular mechanism, that guides tumour environment, still remains unknown. Exploring the underlying molecular mechanisms that orchestrate these phenomena has been the aim of our study.

A co-culture of canine mammary cancer cells and macrophages was established and maintained for 72 hrs. Having sorted the cells, gene expression in cancer cells and macrophages, using DNA microarrays, was examined. The results were confirmed using real-time $\mathrm{QPCR}$ and confocal microscopy. Moreover, their ability for migration and invasion has been assessed.
\end{abstract}

Results: Microarray analysis showed that the up-regulated genes in the cancer cell lines are involved in 15 highly over-manifested pathways. The pathways that drew our diligent attention included: the inflammation pathway mediated by chemokine and cytokine, the Toll receptor signalling pathway and the B cell activation. The upregulated genes in the macrophages were involved in only 18 significantly over-manifested pathways: the angiogenesis, the p53 pathway feedback loops 2 and the Wnt signalling pathway. The microarray analysis revealed that co-culturing of cancer cells with macrophages initiated the myeloid-specific antigen expression in cancer cells, as well as cytokine/chemokine genes expression. This finding was confirmed at mRNA and protein level. Moreover, we showed that macrophages increase cancer migration and invasion.

Conclusions: The presence of macrophages in the cancer environment induces acquisition of the macrophage phenotype (specific antigens and chemokines/cytokines expression) in cancer cells. We presumed that cancer cells also acquire other myeloid features, such as: capabilities of cell rolling, spreading, migration and matrix invasion (what has also been confirmed by our results). It may, perhaps, be the result of myeloid-cancer cell hybrid formation, or cancer cells mimicking macrophages phenotype, owing to various proteins secreted by macrophages.

\section{Background}

Solid tumours comprise cancer cells, resident stromal cells, and migratory haemopoietic cells. Intricate interactions between the cell types regulate tumour growth, progression, metastasis, and angiogenesis. Macrophages are an important element of these microenvironment

\footnotetext{
* Correspondence: magdalena_krol@sggw.pl

'Department of Physiological Sciences, Faculty of Veterinary Medicine, Warsaw University of Life Sciences - WULS, Nowoursynowska 159, 02-776

Warsaw, Poland

Full list of author information is available at the end of the article
}

interactions [1]. They may represent either M1 or M2 phenotype. The classical activation by microbial products is that of the M1 phenotype (also thought to have anti-tumour properties), whereas alternative activation (caused by cancer cells) drives macrophages conversion toward the M2 phenotype. Cancer cells are known to release various chemoattractants which recruit macrophages to colonize the tumour site [2]. On the other hand, counter-activated tumour-associated macrophages (TAMs) produce chemokines, cytokines, growth and angiogenic factors $[1,3]$, thus they actively contribute to
C Biomed Central

(C) 2012 Król et al; licensee BioMed Central Ltd. This is an Open Access article distributed under the terms of the Creative Commons Attribution License (http://creativecommons.org/licenses/by/2.0), which permits unrestricted use, distribution, and reproduction in any medium, provided the original work is properly cited. 
tumour progression and their transition to malignancy. Exploring the underlying molecular mechanisms of this phenomenon seems to be utterly important. Therefore, to view and explain the molecular interactions between the cancer cells and TAMs, we established an in vitro co-culture and conducted a global gene expression analysis using DNA microarrays of macrophages and cancer cells. Neither there is an abundance of microarray data on the global gene expression in TAMs $[2,4,5]$ available, nor there is much information on the changes of cancer cells and their gene expression whilst cultured with macrophages.

The findings confirm that cancer cells under co-culture conditions acquired the macrophage-specific antigen expression. It could as well be indicative of these cells also having other phenotypic characteristics of macrophages, such as: capabilities of cell rolling, spreading, diapedesis, or migration, that allow the metastasis process. Our in vitro studies confirmed that macrophages enhance tumour migration and invasion.

\section{Methods}

\section{Cell lines}

The cell lines used for the study have previously been used in other published research [6-9]. Two canine mammary adenocarcinoma cell lines (CMT-W1, CMTW2), anaplastic cancer cell line (P114), simple carcinoma cell line (CMT-U27) and spindle-cell mammary tumor cell line (CMT-U309) were examined. CMT-W1 and CMT-W2 cell lines were kindly donated by Prof. Dr. Maciej Ugorski and Dr. Joanna Polanska from Wroclaw University (Poland), CMT-U27 cell line was kindly donated by Dr. Eva Hellmen from Swedish Agricultural University (Sweden) and P114 cell line was kindly donated by Dr. Gerard Rutteman from Utrecht University (The Netherlands).

Cells were cultured under optimal conditions: a medium RPMI-1640 enriched with 10\% (v/v) heat-inactivated fetal bovine serum (FBS), penicillin-streptomycin (50 iU mL-1), and fungizone $(2.5 \mathrm{mg} \mathrm{mL}-1)$ (reagents obtained from Sigma Aldrich, USA), in an atmosphere of $5 \% \mathrm{CO} 2$ and $95 \%$ humidified air at $37^{\circ} \mathrm{C}$, and routinely subcultured every other day.

\section{Canine blood mononuclear cell separation}

The anticoagulated whole blood from healthy dogs (patients of the Department of Small Animal Diseases with Clinic, Faculty of Veterinary Medicine, Warsaw University of Life Sciences, Poland) was collected for routine diagnostic purposes (in that case the ethical committee permission is not required). The remaining volume of the blood samples was taken to our analyses (with the written permission of the dog's owners) and immediately subjected to a mononuclear cell separation using Accuspin System-Histopaque 1077 (Sigma Aldrich, USA) according to the manufacturer's protocol. The blood specimen was placed on a porous high-density polyethylene barrier, separating lower chamber containing the Histopaque-1077 solution, in a sterile centrifuge tube. The tube was centrifuged at $800 \times g$ for $30 \mathrm{~min}$ at room temperature. On centrifugation, erythrocytes and granulocytes descend through the frit to pellet below the Histopaque-1077. Lymphocytes and monocytes remained above the frit on the plasma-Histopaque-1077 interface. This layer of cells was aseptically removed with a pipette and transferred to a sterile 15-ml centrifuge tube. Then, the cells were washed with PBS once and subjected to further procedures.

\section{Monocyte sorting and culturing}

The isolated mononuclear blood cells were incubated for an hour at room temperature with mouse monoclonal anti-CD64 FITC-conjugated (Becton Dickinson, USA) antibodies (specific for monocytes/macrophages and minimally specific for granulocytes) applied in a volume recommended by the manufacturer of $20 \mu \mathrm{l}$ per $10^{6}$ cells suspended in $100 \mu \mathrm{l}$. The leukocytes were analyzed using FACS Aria II (Becton Dickinson, USA). The monocytes were at first identified and gated based on the morphological criteria (SSC v/s FSC cytogram) as an intermediate in size (FSC) and with an intricate nuclear configuration (intermediate SSC) cells (Figure 1A). The cytogram showed that most of the granulocytes were eliminated during the mononuclear cells isolation. Then, the CD64-positive cells were gated (Figure 1B) and specificity of staining was checked, showing only the CD64positive cells on the cytogram (Figure 1C).

The CD64-positive monocytes were then separated and grown as a co-culture with cancer cells, as well as a mono-culture. The culturing conditions were the same as those for cancer cells. According to the subject data, culturing of monocytes for 72 hrs is sufficient for their differentiation towards macrophages $[10,11]$.

\section{Co-culture}

In this model, cancer cells (CMT-W1, CMT-W2, CMTU27, CMT-U309, P114) were grown on separated flasks, and sorted monocytes were then layered on the top of each cell line. An Orange CellTracker fluorescent dye CMTMR (Invitrogen, USA) was used to stain the cancer cells population before the sorted monocyte population was added. Staining was accomplished by incubation in serum/antibiotics-free RPMI medium containing $5 \mu \mathrm{M}$ CMTMR (10 mM stock in DMSO; Sigma Aldrich, USA) for $45 \mathrm{~min}$ at $37^{\circ} \mathrm{C}$. Subsequently, the medium was aspirated, and the cancer cells were washed twice with PBS and incubated with complete RPMI for $1 \mathrm{hr}$. Sorted 


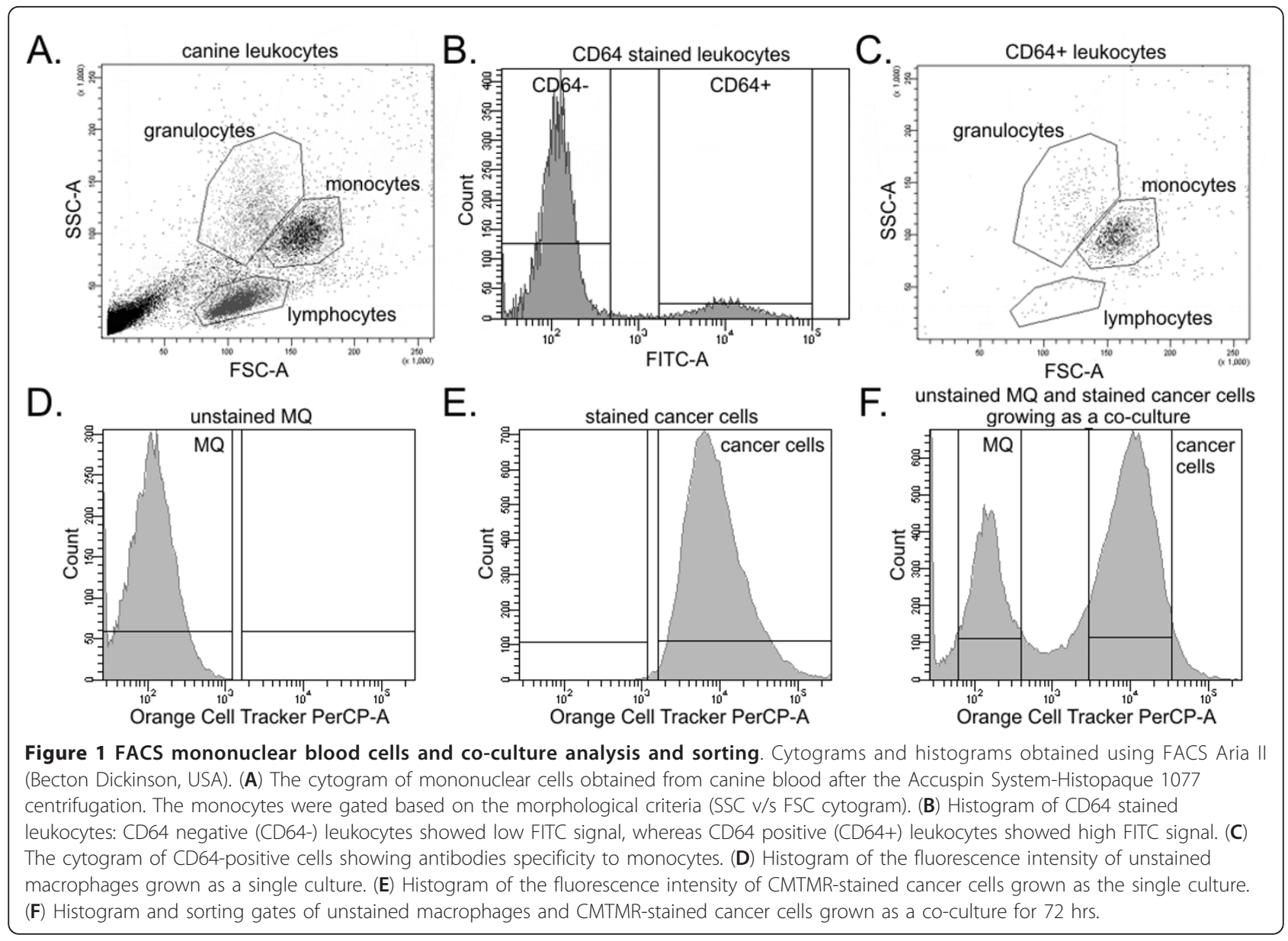

monocytes were placed on the CMTMR-stained cancer cells.

The co-culture was maintained for at least $72 \mathrm{~h}$. Then, the co-cultured cells were harvested by trypsynization and sorted using FACS Aria II (Becton Dickinson, USA) into two tubes: unstained macrophages and stained cancer cells (Figures 1D, E, F and 2).

\section{RNA isolation, validation, amplification, reverse transcription, labeling and hybridization}

The sorted macrophages and cancer cells grown as the co-culture were centrifuged ( $2500 \mathrm{rpm}$ for $5 \mathrm{~min}$ ) in separated tubes, whereas cancer cells and macrophages grown as mono-cultures were washed with PBS and next scraped and centrifuged (2500 rpm for $5 \mathrm{~min}$ ) in separated tubes. The total RNA from the samples was isolated using a Total RNA kit (A\&A Biotechnology, Poland) according to the manufacturer's protocol. Isolated RNA samples were dissolved in RNase-free water. The quantity of RNA was measured using NanoDrop (NanoDrop Technologies, USA). The samples with adequate amounts of RNA were treated with DNaseI to eliminate a possibility of DNA contamination. The samples were subsequently purified using RNeasy MiniElute Cleanup Kit (Qiagen, Germany). Finally RNA samples were analyzed using BioAnalyzer (Agilent, USA) to measure the final RNA quality and integrity.

The Quick Amp Labeling Kit (Agilent, USA) was used to amplify and label target RNA to generate complementary RNA (cRNA) for oligo microarrays used in gene expression profiling and other downstream analyses. The gene expression of each cancer cell line, grown under co-culture conditions with macrophages, was compared against the gene expression of the same cancer cell line grown as a mono-culture (gene expression in CMT-U27 cell line grown as a co-culture with macrophages was compared to gene expression in CMT-U27 cell line grown as a mono-culture; gene expression in CMT-U309 cell line grown as a co-culture with macrophages was compared to gene expression in CMT-U309 cell line grown as a mono-culture; gene expression in P114 cell line grown as a co-culture with macrophages was compared to gene expression in P114 cell line grown as a mono-culture; gene expression in CMT-W1 cell line grown as a co-culture with 


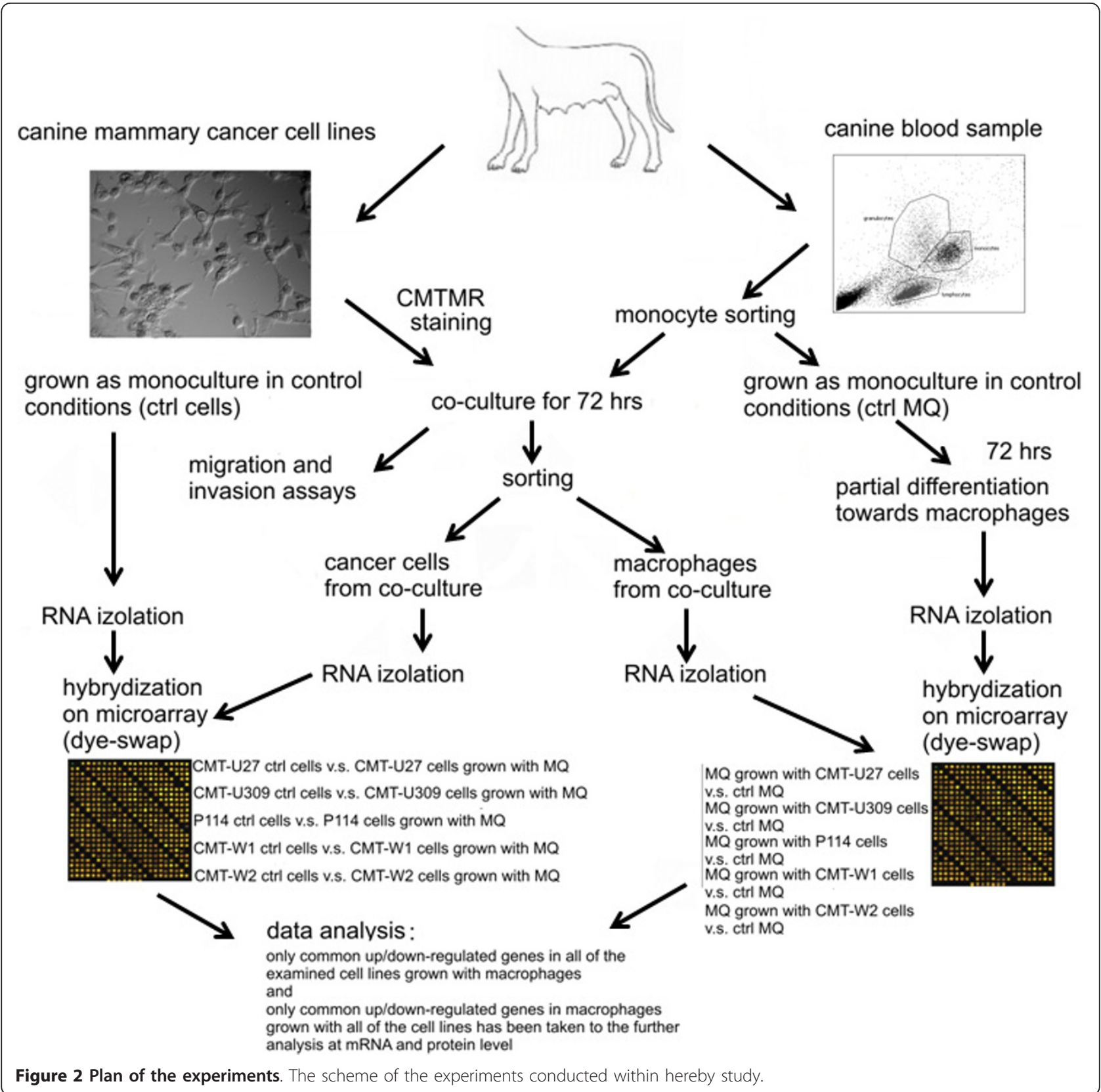

macrophages was compared to gene expression in CMT-W1 cell line grown as a mono-culture; gene expression in CMT-W2 cell line grown as a co-culture with macrophages was compared to gene expression in CMT-W2 cell line grown as a mono-culture). The gene expression of macrophages grown as a co-culture with cancer cell lines was compared against the gene expression of macrophages grown as the mono-culture. Each sample was examined in a dye-swap to eliminate the effect of label factor. Thus, each biological condition was labelled once by Cy3 and once by Cy5. Taking the average of two labelled arrays, the dye effect on any particular gene was cancelled. The hybridization was performed with canine-specific AMADID Release GE 4 $\times 44 \mathrm{~K}$ microarrays (Agilent, USA) using Gene Expression Hybridization Kit (Agilent, USA) according to the manufacturer's protocol.

Signal detection, quantification and analysis

Acquisition and analysis of hybridization intensities were performed using DNA microarray scanner (Agilent, USA). Then, the results were extracted using Agilent's Feature Extraction Software with normalization and robust statistical analyses. Results were analyzed for 
statistical purposes using Feature Extraction and Gene Spring software (Agilent, USA). The unpaired $t$-test with Benjamin-Hochberg FDR $<5 \%$ (false discovery rate) correction was applied (with $\mathrm{p}$ value cut-off $<0.01$ ). For further analysis we hierarchically clustered the genes and chose only those with values within upper and lower cut-off (100.00 and 20.00, respectively) in each of the slide. We analyzed only genes that were regulated in all the examined samples within the group (that is: in all the cell lines grown with macrophages and in all the macrophages samples grown with cell lines) whose expression changed at least 3-fold in each of examined slide. In this experimental model we examined each of the sample in duplicate (dye-swap), whereas significant genes were chosen from five biological repetitions (five various cell lines). The area of the analyses covered in this publication has been deposited in NCBI's Gene Expression Omnibus and is accessible via GEO Series accession number GSE29339.

Gene function was identified using the PANTHER pathway analysis software [12] and Pathway Studio software (Agilent, USA). PANTHER on-line platform allowed for wide analysis of the Canis familiaris regulated genes and also for statistical analysis of number of regulated genes involved in specific pathways or biological functions compared to the normal healthy cell of this specie.

\section{Real-time qPCR}

The mRNA sequences of the key genes were obtained from NCBI database. Primers were designed using PRIMER3 software (free on-line access) and checked using Oligo Calculator (free on-line access) and Primer-Blast (NCBI database). Primers' sequences are listed in Table 1. HPRT and RPS19 genes were used as non-regulated, reference genes for normalization of target gene expression [13,14]. Quantitative RT-PCR was performed using fluorogenic Lightcycler Fast Strand DNA Sybr Green (Roche) and the Light Cycler (Roche). The results were analyzed using comparative Ct method [15]. Relative transcript abundance of the gene equals $\Delta \mathrm{Ct}$ values $\left(\Delta \mathrm{Ct}=\mathrm{Ct}^{\text {reference }}-\mathrm{Ct}^{\text {target }}\right)$. Relative changes in transcript are expressed as $\Delta \Delta \mathrm{Ct}$ values $\left(\Delta \Delta \mathrm{Ct}=\Delta \mathrm{Ct}^{\text {control condi- }}\right.$ tions $\left.-\Delta C \mathrm{t}^{\mathrm{co}-\text { culture conditions }}\right)$. The experiment was conducted in triplicates.

\section{Immunohistochemistry (IHC)}

The cells were cultured on Lab-Tek (Nunc Inc., USA) 4chamber culture slides and were fixed with ethanol after 24 hrs.

The samples were incubated in the Peroxidase Blocking Reagent (Dako, Denmark) for $10 \mathrm{~min}$ at room temperature prior to the antibody incubation. After $30 \mathrm{~min}$ incubation in $5 \%$ bovine serum albumin (Sigma Aldrich, Germany), the rabbit polyclonal MCSF Receptor (other designations: MCSF-R or CSF-1R) obtained from Abcam (United Kingdom) primary antibodies were used (diluted in $1 \%$ bovine serum). According to the manufacturer's instructions the slides were incubated with antibodies at $+4^{\circ} \mathrm{C}$ overnight. For the staining the EnVision kit (Labelled Polymers consist of secondary anti-rabbit antibodies conjugated with the HRP enzyme complex obtained from Dako) was used. To develop the coloured product, the 3,3'-Diaminobenzidine (DAB) substrate was used (Dako, Denmark). Finally, the haematoxylin was used for nuclei counterstaining.

Each slide was photographed 10 times using Olympus microscopy BX60. The colorimetric intensity of the CSF-1R expression reflected as IHC-stained antigen spots (brown colour) were counted by a computerassisted image analyzer (Olympus Microimage ${ }^{\mathrm{TM}}$ Image

Table 1 Primers used for real-time qPCR

\begin{tabular}{|c|c|c|c|c|}
\hline Gene symbol & Forward primer & Reverse primer & Optimum annealing temp. $\left({ }^{\circ} \mathrm{C}\right)$ & Optimum annealing time (sec) \\
\hline CCL2 & CTCCAGTCACCTGCTGCTAT & CACAGCTTCTTTGGGACACT & 60 & 4 \\
\hline$\overline{C C L 3}$ & CCAGGTCTTCTCACCATTTG & AGATAATACCGGGCTTGGAG & 60 & 5 \\
\hline CD163 & ATGTCCAGTGTCCAAAAGGA & CATGTGATCCAGGTCTCCTC & 61 & 6 \\
\hline$\overline{\text { CSF1R }}$ & TGCAGTTTGGGAAGACTCTC & TGTGGACTTCAGCATCTTCA & 60 & 4 \\
\hline HIF1 & GATTGCAGCTCCATCTCCTA & TCCTITCCTGCTCTGTITG & 58 & 5 \\
\hline IL18 & GATATGCCCGATTCTGACTG & GCCTGGAACACTTCTCTGAA & 60 & 9 \\
\hline$\overline{M M P 9}$ & CGACTACGACCAGGACAAAC & AAGCCCCACTTCTTGTCTCT & 61 & 8 \\
\hline VEGF-C & CAGCAACACTACCACAGTGC & CTCCAGAATTTGAGGCAAAA & 61 & 5 \\
\hline Wnt7b & GCGGAGGGCTGTGTATAAGA & GTCCCCTACTITGCGGAACT & 59 & 5 \\
\hline HPRT & AGCTTGCTGGTGAAAAGGAC & TTATAGTCAAGGGCATATCC & 59 & 6 \\
\hline RPS19 & CCTTCCTCAAAAAGTCTGGG & GTTCTCATCGTAGGGAGCAAG & 61 & 10 \\
\hline
\end{tabular}

Primers sequences used in this study and their annealing optimal temperature and time. The mRNA sequences of key genes were obtained from NCBI database. Primers were designed using PRIMER3 software (free on-line access) and checked using Oligo Calculator (free on-line access) and Primer-Blast (NCBI database). Primers sequences are listed in Table 1. HPRT and RPS19 genes were used as non-regulated reference genes for normalization of target gene expression [3,9] 
Analysis, software version 4.0 for Windows, USA). The antigen spot colour intensity is expressed as a mean pixel optical density on a 1-256 scale.

\section{Confocal microscopy}

The co-culture of cancer cells with macrophages was conducted as described above. The cancer cells grown as mono-culture and as a co-cultures were stained using Orange CellTracker fluorescent dye CMTMR, as described above. Cancer cells and macrophages grown as mono-cultures, as well as the co-culture were fixed with $70 \%$ ethanol (10 $\mathrm{min}$ ) and washed three times in PBS. Cells were permeabilized with $0.5 \%$ Triton X-100/ PBS (10 min), washed with PBS twice and incubated for $1 \mathrm{hr}$ at room temperature with: mouse monoclonal antiCD64 FITC-conjugated (Becton Dickinson, USA) antibodies (20 ul per $10^{6}$ cells) and mouse monoclonal antiCD14 FITC-conjugated (LifeSpan Biosciences, USA) antibodies (10 ul per $10^{6}$ cells) according to the manufacturer's instructions. The cells were then washed three times with PBS and the coverslips were mounted on microscope slides using ICN mounting medium.

The cell imaging was performed by confocal laser scanning microscope FV-500 system (Olympus Optical Co, Germany). The combination of excitation/emission were: Argon $488 \mathrm{~nm}$ laser with 505-525 nm filter for FITC and HeNe $543 \mathrm{~nm}$ laser with $610 \mathrm{~nm}$ filter for CMTMR staining. The pictures were gathered separately for each fluorescence channel. The cells were examined using the Fluoview program (Olympus Optical Co., Germany).

\section{Wound-healing assay}

To assess the ability to migration of cancer cells grown as a co-culture with macrophages, we applied a woundhealing test. The cancer cells (grown as the co-culture with macrophages and normal control cells) were separately seeded in multi-well plates and then (after $24 \mathrm{hrs}$ when the cells were confluent), using a pipette tip (100 ul) a straight scratch has been made, simulating a wound. The images were captured at the beginning and at regular intervals (after 2, 4 and 6 hrs) during cell migration to close the wound. The images then were compared to quantify migration rate of the cells. This method is particularly suitable for studies of cell-cell interaction on cell migration [16]. The pictures has been analyzed using a computer-assisted image analyzer (Olympus Microimage ${ }^{\mathrm{TM}}$ Image Analysis, software version 4.0 for Windows, USA).

\section{Invasion assay}

BD BioCoat Matrigel ${ }^{\mathrm{TM}}$ invasion chambers (BD Biosciences, USA) pre-coated with BD Matrigel matrix were used according to the manufacturer's protocol. The assay insert plates were prepared by rehydrating the BD Matrigel Matrix coating with phosphate buffered saline for two hrs at $37^{\circ} \mathrm{C}$. The rehydration solution was carefully removed, $2.5 \times 10^{5}$ of control cancer cells or cancer cells grown as co-culture with macrophages (at the ratio of 10:1) was added to each apical chamber and $0.75 \mathrm{ml} \mathrm{RPMI-1640}$ containing chemoattractant (10\% FBS) was added to the basal chamber. Uncoated insert plates, included as invasion controls, were used without rehydration. Assay plates were incubated for $22 \mathrm{hrs}$ at standard culturing conditions. 2.5 $\mu \mathrm{g} / \mathrm{ml}$ Calcein AM were added to $20 \mu \mathrm{l}$ DMSO and then, $10 \mu \mathrm{l}$ was transferred to $12 \mathrm{ml}$ Hanks Buffered Saline Dispense. $0.5 \mathrm{ml}$ Calcein solution was then transferred into each well of 24-well plate. The medium from insert was removed and multiwell inserts were transferred to the plate containing $0.5 \mathrm{ml} /$ well calcein. Plates were incubated an hour at standard culture conditions. The fluorescence of invaded cells was measured with excitation wave length $485 \mathrm{~nm}$ and emission wave length Em $530 \mathrm{~nm}$ using Tecan Infinite 200 Reader (Tecan, Switzerland).

\section{D culture}

Cancer cells were treated with trypsin and resuspended in culture medium. $35 \mathrm{~mm}$ culture plates (Corning Inc., USA) were coated with $100 \mu \mathrm{l}$ of growth factor reduced Matrigel (BD Biosciences, USA) and left to solidify for 30 min. at $37^{\circ} \mathrm{C}$. The cells were then plated at a concentration of $10^{4}$ cells $/ \mathrm{ml}$. The growth of cells on Matrigel was observed every day under phase-contrast microscope.

\section{Statistical analysis}

The analysis for statistical purposes was conducted using Prism version 5.00 software (GraphPad Software, USA). The two-way ANOVA, ANOVA + Tukey HSD (Honestly Significant Difference) post-hoc test and $t$-test were applied. The $\mathrm{p}$-value $<0.05$ was regarded as significant whereas $\mathrm{p}$-value $<0.01$ and $\mathrm{p}$-value $<0.001$ as highly significant.

\section{Results}

\section{Sorting of the co-cultured cells}

Flow cytometry had easily distinguished the CMTMRstained cells from the unstained macrophages (Figure $1 D, E)$ and allowed a further proper sorting of each population (Figure 1F). The co-culture was maintained for at least $72 \mathrm{~h}$. The differential staining prolonged for such period of time (Figure 1E, F and see also confocal microscopy results) showed no detrimental effect on proliferation and plating efficiency. The fluorescence intensity of the stained cancer cells after the 3-days coculture with macrophages was the same as that of the control cancer cells grown as a mono-culture (Figure 1E, F; see also confocal microscopy results). Similar culture conditions had previously been described [17]. 
Our FACS sorting isolated a 97-99\% pure population on postsort, with a positive result comparable to other reported data available [5]. Sorting purity was also assessed using fluorescence microscopy (showing no stained cells in macrophages tube and no unstained cells in cancers tube).

\section{Monocyte differentiation}

The morphological assessment of the monocytes culture (obtained from the sorted CD64-positive monocytes) using confocal microscopy confirmed that after the 72 hrs they were partially differentiated into macrophages (Figure 3) despite no stimulation with growth factors. These results are consistent with the data available on the subject, showing that the 3-day monocyte culturing leads to their partial differentiation toward the macrophages phenotype $[10,11]$. The colonies were stained using anti-CD14, and anti-CD64 antibodies (Figure 3). Analysis of stained cells and image contrast obtained with Nomarski Interference Contrast (representative pictures are shown at Figure 3) showed that all the macrophages expressed CD14 antigen as well as CD64 what

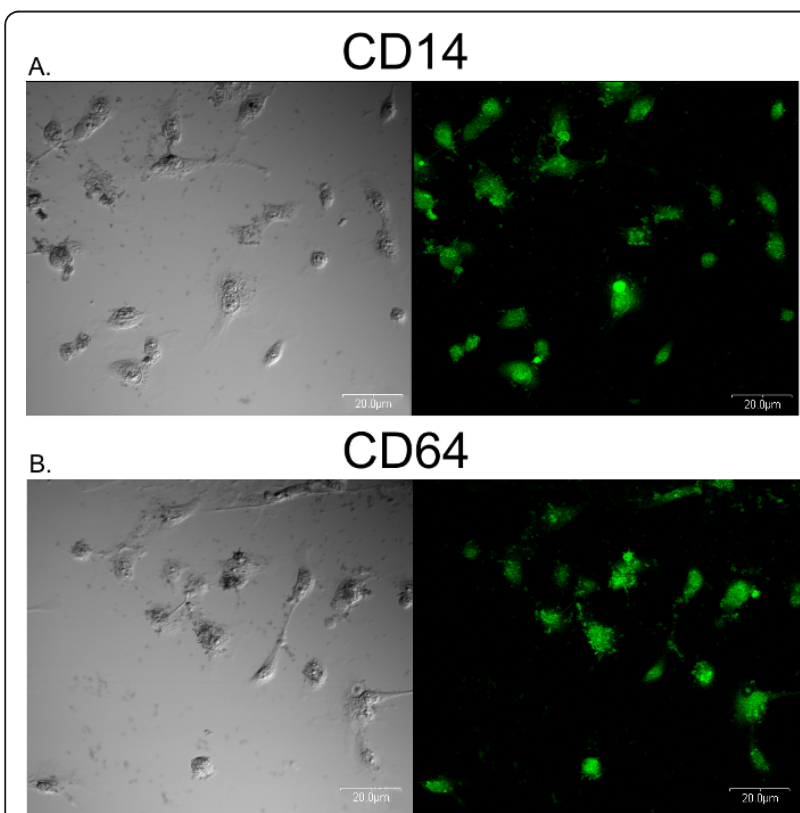

Figure 3 Monocytes differentiation toward macrophages after 72 hrs of culture. The pictures of CD64-positive monocytes sorted from mononuclear blood cells and cultured for $72 \mathrm{hrs}$ showing their partial differentiation toward macrophages. (A) Macrophages grown as a mono-culture were stained using anti-CD64 FITC-conjugated antibodies (Becton Dickinson, USA). (B) Macrophages grown as a mono-culture were stained using anti-CD14 FITC-conjugated antibodies (LifeSpan Biosciences, USA). Cells were pictured by confocal laser scanning microscope FV-500 system (Olympus Optical Co, Germany). The cells were examined using the Fluoview program (Olympus Optical Co., Germany). can also confirm monocyte differentiation towards macrophages [18].

\section{Global gene expression analysis}

The Gene Spring (Agilent, USA) hierarchical clustering depicted similar gene expression in each of the dyeswap experiments (Figure 4) what indicates that all microarray samples were successfully labelled, hybridized, scanned and that they are highly reproducible. The unpaired $t$-test with Benjamin-Hochberg FDR $<5 \%$ (false discovery rate) correction (with p value cut-off < 0.01) and further PANTHER analysis revealed 43 upregulated and 4 down-regulated genes in cancer cells grown in co-culture with macrophages with values within upper and lower cut-off (100.00 and 20.00, respectively) in each of the slide (Table 2). Only the genes whose expression had changed at least 3-fold in each of the examined slide were chosen for further analyses. These up/down-regulated genes were common for each cell line examined individually, when compared with the same cell line grown as a mono-culture.

The unpaired $t$-test with Benjamin-Hochberg FDR < $5 \%$ (false discovery rate) correction (with p value cutoff $<0.01$ ) and further PANTHER analysis revealed 30 up-regulated and 25 down-regulated genes in monocytes/macrophages grown as co-culture with cancer cells with values within upper and lower cut-off (100.00 and 20.00, respectively) in each of the slide (Table 3). Only the genes whose expression had changed at least 3-fold in each of examined slide were chosen for further analyses. These differentially expressed genes were common for macrophages grown with each cell line individually in comparison to macrophages grown as the mono-culture.

\section{Over- representation of pathways in cells grown under} co-culture conditions

The PANTHER binomial statistics tool allowed us to statistically determine over-manifestation of PANTHER pathways classification categories.

The 15 significantly over-manifested $(\mathrm{p}<0.05)$ pathways were observed in cancer cells grown as a co-culture (Table 4). Most of the up-regulated genes in cancer cells lines were involved in the stimulation of 1 . inflamation mediated by chemokine and cytokine signaling pathways, 2 . Toll receptor signalling pathway (7 genes, $\mathrm{p}$ $=9.44 \mathrm{E}-06)$, and 3 . B cell activation (7 genes, $\mathrm{p}=6.8 \mathrm{E}-$ 05).

Other important over-manifested pathways are apoptosis signaling pathway ( 6 genes, $\mathrm{p}=3.86 \mathrm{E}-04)$, interleukin signaling pathway (6 genes, $\mathrm{p}=8.86 \mathrm{E}-03)$ and PDGF signaling pathway (5 genes, $\mathrm{p}=3.99 \mathrm{E}-02)$. The downregulated genes in the cancer cells were not involved in any significantly over- manifested pathways. 


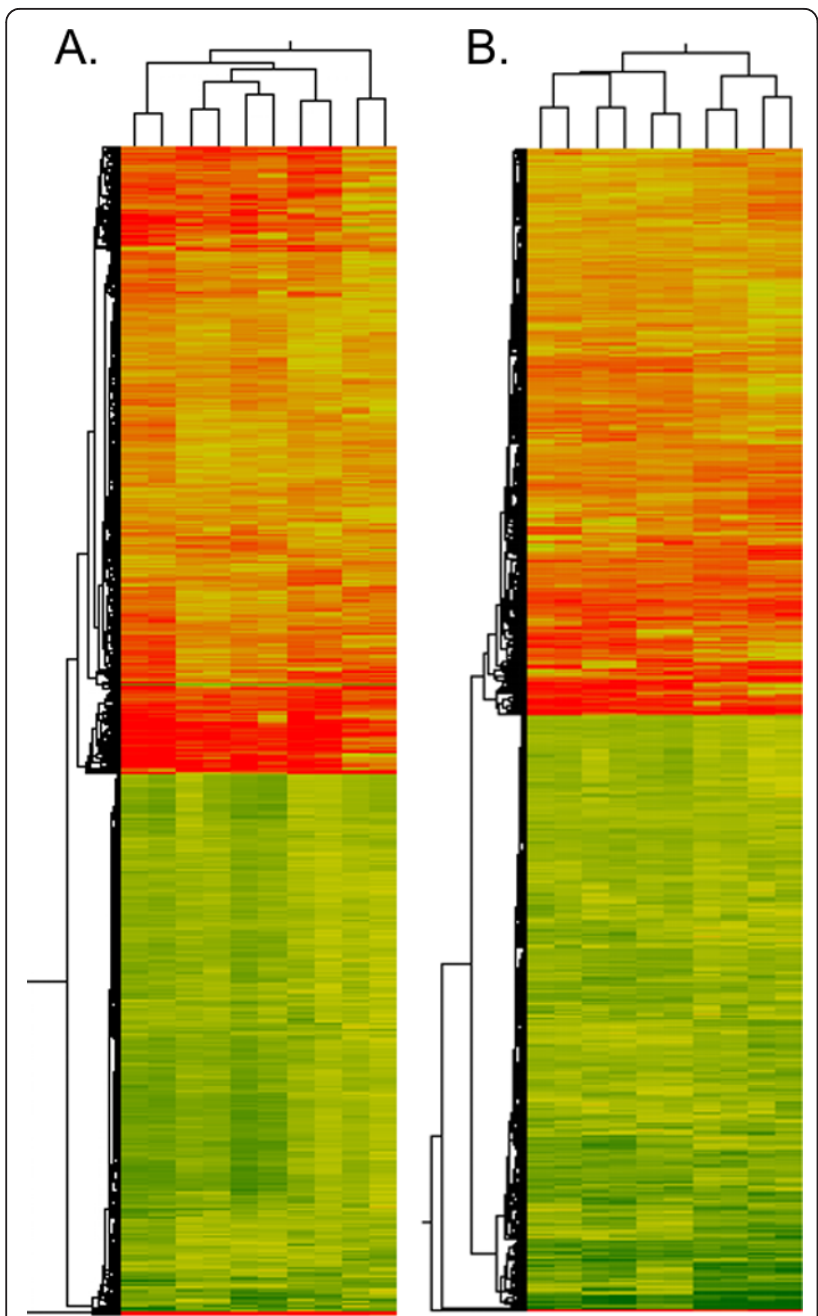

Figure 4 Hierarchical clustering of gene expression in canine mammary cancer cell lines and macrophages grown as a coculture. Gene Spring (Agilent, USA) diagrams of gene expression clustering of (A) canine mammary cancer cell lines grown as a coculture with macrophages and (B) macrophages grown as a coculture with cancer cells in both microarray experiments (dyeswaps) shows highly repeatable results. Each row represents a single gene, and each column an experimental sample (from the left: at A. panel: CMT-U27, CMT-U309, P114, CMT-W1 and CMT-W2 cell lines grown with macrophages; at B. panel: macrophages grown with CMT-U27, CMT-U309, P114, CMT-W1 and CMT-W2 cell lines). In each sample, the ratio of the abundance of transcripts of each gene to the mean abundance of the gene's transcript, among all the samples is represented by the colour: green squares, transcript levels below the mean; red squares, transcript levels greater than the mean. Colour saturation reflects the magnitude of the ratio relative to the mean for each set of samples. Dendrogram represents similarities in the expression patterns between experimental samples.

The up-regulated genes in the macrophages were involved in 18 over-manifested pathways (Table 5): angiogenesis (13 genes, $\mathrm{p}=1.17 \mathrm{E}-04)$, p53 pathway feedback loops2 (6 genes, $\mathrm{p}=2.16 \mathrm{E}-04)$, Wnt signaling pathway (17 genes, $\mathrm{p}=2.90 \mathrm{E}-04)$. Other important pathways are: inflammation mediated by chemokine and cytokine signaling pathway (12 genes, $\mathrm{p}=0.09 \mathrm{E}-03)$ and FGF signaling pathway (6 genes, $\mathrm{p}=4.05 \mathrm{E}-02)$.

\section{Over-representation of genes involved in particular biological processes in cells grown under co-culture conditions}

The PANTHER binomial statistics tool allowed us to statistically determine over-manifestation of PANTHER biological processes classification categories. The most important biological processes in cancer cells grown as a co-culture were: macrophage activation (21 genes, $\mathrm{p}=$ 6.24E-11), cell motion (28 genes, $\mathrm{p}=7.49 \mathrm{E}-06$ ), mammary gland development ( 5 genes, $\mathrm{p}=2.17 \mathrm{E}-03$ ), cellcell adhesion (19 genes, $\mathrm{p}=5.06 \mathrm{E}-03)$, angiogenesis (11 genes, $\mathrm{p}=9.51 \mathrm{E}-03)$.

The most important biological processes in macrophages grown as a co-culture were cell-matrix adhesion (10 genes, $\mathrm{p}=3.92 \mathrm{E}-03)$ and cell-cell adhesion (28 genes, $\mathrm{p}=5.79 \mathrm{E}-03)$.

\section{The results were confirmed at mRNA level using real-time} qPCR analysis

For the purposes of the microarray data validation, we have selected 9 genes that may play the most important role in cancer cells-macrophages interactions: CCL2, CCL3, CD163, CSF1R, HIF1, Il-18, MMP9, VEGF-C, and Wnt7b. Real-time qPCR results showed similar trends in gene expression modulations as were observed in microarray studies. The real-time qPCR confirmed the CCL2, CCL3, CD163, CSF1R, MMP9, HIF1, VEGF$\mathrm{C}$ up-regulation in cancer cells grown as a co-culture with macrophages. The analysis also confirmed downregulation of CCL2, IL18, and up-regulation of Wnt7b genes in macrophages grown under co-culture conditions with cancer cells (Table 6).

\section{Confocal microscopy and IHC analysis revealed myeloid- lineages markers expression in cancer cells following the co-culturing with macrophages}

The microarray analysis revealed that the co-culturing of cancer cells with macrophages initiated the myeloid-specific antigens expression in cancer cells. Thus, to confirm this data the confocal analysis was conducted. The expression of two monocytes/macrophages-specific antigens was assessed: CD14 and CD64. The cancer cells grown as mono-culture did not show expression of both antigens (Figure 5A, B left panel), whereas the strong expression of these two markers was detected when the cancer cells were co-cultured with macrophages (Figure $5 \mathrm{~A}, \mathrm{~B}$ right panel). The confocal observations also showed that macrophages co-exist closely with the cancer cells, even forming cell fusions. 
Table 2 Up/down-regulated genes in canine mammary cancer cell lines grown as co-culture with macrophages

\begin{tabular}{|c|c|c|c|}
\hline No. & Fold change & Gene symbol & Gene name \\
\hline 1 & $\uparrow 3.25$ & ANPEP & Aminopeptidase N \\
\hline 2 & $\uparrow 3.83$ & ATP6V0E1 & V-type proton ATPase subunit e 1 \\
\hline 3 & $\uparrow 4.98$ & C5AR1 & C5a anaphylatoxin chemotactic receptor \\
\hline 4 & $\uparrow 4.86$ & $\mathrm{CCL} 2$ & C-C motif chemokine 2 \\
\hline 5 & $\uparrow 5.23$ & CCL3 & C-C motif chemokine 3 \\
\hline 6 & $\uparrow 4.28$ & CCL4 & C-C motif chemokine 4 \\
\hline 7 & $\uparrow 3.99$ & CCL5 & C-C motif chemokine 5 \\
\hline 8 & $\uparrow 3.91$ & CCL8 & C-C motif chemokine 8 \\
\hline 9 & $\uparrow 3.03$ & CCR1 & CCR1 \\
\hline 10 & $\uparrow 3.66$ & CCR5 & C-C chemokine receptor type 5 \\
\hline 11 & $\uparrow 4.47$ & CD163 & Soluble CD163 \\
\hline 12 & $\uparrow 3.55$ & CD40 & Tumor necrosis factor receptor superfamily member 5 \\
\hline 13 & $\uparrow 4.89$ & CD80 & CD80 \\
\hline 14 & $\uparrow 4.31$ & CD86 & CD86 \\
\hline 15 & $\uparrow 3.38$ & $\operatorname{cox} 17$ & Cytochrome c oxidase copper chaperone \\
\hline 16 & $\uparrow 3.62$ & CSF2 & Granulocyte-macrophage colony-stimulating factor \\
\hline 17 & $\uparrow 3.53$ & CSF3 & Granulocyte colony-stimulating factor \\
\hline 18 & $\uparrow 3.68$ & CSF1R & Colony stimulating factor receptor 1 \\
\hline 19 & $\uparrow 3.09$ & CTSC & Dipeptidyl-peptidase 1 light chain \\
\hline 20 & $\uparrow 5.06$ & CTSK & Cathepsin K \\
\hline 21 & $\uparrow 5.92$ & CTSS & Cathepsin S \\
\hline 22 & $\uparrow 3.5$ & CXCR7 & C-X-C chemokine receptor type 7 \\
\hline 23 & $\uparrow 3.26$ & DLA-64 & DLA-64 \\
\hline 24 & $\uparrow 3.26$ & EMR1 & EMR1 \\
\hline 25 & $\uparrow 3.31$ & FTH1 & Ferritin heavy chain \\
\hline 26 & $\uparrow 3.1$ & FTL & Ferritin light chain \\
\hline 27 & $\uparrow 5.25$ & $\mathrm{IL} 1 \mathrm{~A}$ & Interleukin-1 alpha \\
\hline 28 & $\uparrow 5.07$ & IL1B & Interleukin-1 beta \\
\hline 29 & $\uparrow 3.45$ & IL6 & Interleukin-6 \\
\hline 30 & $\uparrow 5.6$ & IL8 & Interleukin-8 \\
\hline 31 & $\uparrow 3.09$ & MMP9 & Matrix metalloproteinase- 9 \\
\hline 32 & $\uparrow 4.83$ & MX1 & Interferon-induced GTP-binding protein $\mathrm{Mx1}$ \\
\hline 33 & $\uparrow 3.34$ & NPC2 & Epididymal secretory protein E1 \\
\hline 34 & $\uparrow 3.19$ & OOEP & Oocyte-expressed protein \\
\hline 35 & $\uparrow 3.6$ & PLA2G7 & Platelet-activating factor acetylhydrolase \\
\hline 36 & $\uparrow 3.23$ & PSAP & Pulmonary surfactant-associated protein A \\
\hline 37 & $\uparrow 4.84$ & PSMB8 & Proteasome subunit beta type- 8 \\
\hline 38 & $\uparrow 3.57$ & PSMB9 & Proteasome subunit beta type \\
\hline 39 & $\uparrow 3.74$ & PTGES & Prostaglandin E synthase \\
\hline 40 & $\uparrow 3.35$ & SLAMF1 & Signaling lymphocytic activation molecule \\
\hline 41 & $\uparrow 3.34$ & SYK & SYK \\
\hline 42 & $\uparrow 4.64$ & TLR2 & Toll-like receptor 2 \\
\hline 43 & $\uparrow 3.55$ & TLR4 & TLR4 \\
\hline 44 & $\downarrow 3.11$ & RXRB & Retinoic acid receptor RXR-beta \\
\hline 45 & $\downarrow 3.17$ & SLC5A3 & Sodium/myo-inositol cotransporter \\
\hline 46 & $\downarrow 3.06$ & MSX2 & Homeobox protein MSX-2 \\
\hline 47 & $\downarrow 5.17$ & KRT13 & Keratin 13 \\
\hline
\end{tabular}


Table 3 Up/down-regulated genes in macrophages grown as a co-culture with canine mammary cancer cells

\begin{tabular}{|c|c|c|c|}
\hline No & Fold change & Gene symbol & Gene name \\
\hline 1 & $\uparrow 5.78$ & $\mathrm{ABCC5}$ & $\mathrm{ABCC5}$ \\
\hline 2 & $\uparrow 3.17$ & ANXA2 & Annexin A2 \\
\hline 3 & $\uparrow 3.22$ & ASPM & Abnormal spindle-like microcephaly-associated protein homolog \\
\hline 4 & $\uparrow 3.0$ & BGN & Biglycan \\
\hline 5 & $\uparrow 5.83$ & CAV1 & Caveolin-1 \\
\hline 6 & $\uparrow 4.04$ & CAV2 & Caveolin-2 \\
\hline 7 & $\uparrow 3.47$ & CCL20 & CCL20 \\
\hline 8 & $\uparrow 3.15$ & COL1A1 & Collagen alpha-1(I) chain \\
\hline 9 & $\uparrow 4.51$ & CSF2 & Granulocyte-macrophage colony-stimulating factor \\
\hline 10 & $\uparrow 4.28$ & CXCL10 & C-X-C motif chemokine 10 \\
\hline 11 & $\uparrow 4.06$ & EGFR & EGFR \\
\hline 12 & $\uparrow 4.66$ & FZD6 & Frizzled-6 \\
\hline 13 & $\uparrow 4.29$ & GATA6 & GATA6 \\
\hline 14 & $\uparrow 3.79$ & IL12A & Interleukin-12 subunit alpha \\
\hline 15 & $\uparrow 3.63$ & IL13RA2 & Interleukin-13 receptor alpha-2 chain \\
\hline 16 & $\uparrow 5.39$ & MMP3 & Stromelysin-1 \\
\hline 17 & $\uparrow 4.58$ & MYC & Myc proto-oncogene protein \\
\hline 18 & $\uparrow 3.51$ & OAT & OAT \\
\hline 19 & $\uparrow 6.54$ & PFKM & 6-phosphofructokinase, muscle type \\
\hline 20 & $\uparrow 3.86$ & PTPLA & Protein-tyrosine phosphatase-like member A \\
\hline 21 & $\uparrow 3.36$ & RAD51 & DNA repair protein RAD51 homolog 1 \\
\hline 22 & $\uparrow 4.86$ & RHPN2 & Rhophilin-2 \\
\hline 23 & $\uparrow 3.05$ & RPL23 & $60 S$ ribosomal protein $\mathrm{L} 23$ \\
\hline 24 & $\uparrow 3.1$ & RPS17 & $40 S$ ribosomal protein S17 \\
\hline 25 & $\uparrow 3.54$ & RPS18 & $40 S$ ribosomal protein S18 \\
\hline 26 & $\uparrow 4.87$ & UACA & Uveal autoantigen with coiled-coil domains and ankyrin repeats \\
\hline 27 & $\uparrow 5.11$ & Wnt5b & wingless-type MMTV integration site family member $5 b$ \\
\hline 28 & $\uparrow 3.78$ & Wnt7a & wingless-type MMTV integration site family member 7a \\
\hline 29 & $\uparrow 4.51$ & Wnt7b & wingless-type MMTV integration site family member $7 \mathrm{~b}$ \\
\hline 30 & $\uparrow 4.11$ & YES1 & Proto-oncogene tyrosine-protein kinase Yes \\
\hline 31 & $\downarrow 3.63$ & ANPEP & Aminopeptidase N \\
\hline 32 & $\downarrow 3.27$ & APOE & Apolipoprotein E \\
\hline 33 & $\downarrow 5.73$ & C5AR1 & C5a anaphylatoxin chemotactic receptor \\
\hline 34 & $\downarrow 5.24$ & CCL13 & C-C motif chemokine 13 \\
\hline 35 & $\downarrow 3.33$ & $\mathrm{CCL} 2$ & C-C motif chemokine 2 \\
\hline 36 & $\downarrow 3.36$ & CCR1 & CCR1 \\
\hline 37 & $\downarrow 3.73$ & CCR5 & C-C chemokine receptor type 5 \\
\hline 38 & $\downarrow 3.66$ & CD86 & CD86 \\
\hline 39 & $\downarrow 3.1$ & CTSK & Cathepsin K \\
\hline 40 & $\downarrow 3.08$ & CXCR7 & C-X-C chemokine receptor type 7 \\
\hline 41 & $\downarrow 3.84$ & $\mathrm{DHDH}$ & dehydrogenase \\
\hline 42 & $\downarrow 4.1$ & EDNRB & Endothelin B receptor \\
\hline 43 & $\downarrow 4.14$ & HTR7 & HTR7 \\
\hline 44 & $\downarrow 3.47$ & IL18 & Interleukin-18 \\
\hline 45 & $\downarrow 3.15$ & IL1B & Interleukin-1 beta \\
\hline 46 & $\downarrow 3.1$ & KCNJ2 & Inward rectifier potassium channel 2 \\
\hline 47 & $\downarrow 3.61$ & MMP9 & Matrix metalloproteinase-9 \\
\hline
\end{tabular}


Table 3 Up/down-regulated genes in macrophages grown as a co-culture with canine mammary cancer cells (Continued)

\begin{tabular}{llll}
\hline 48 & $\downarrow 4.72$ & MYH7 & Myosin-7 \\
\hline 49 & $\downarrow 4.19$ & OR04A01 & olfactory receptor \\
\hline 50 & $\downarrow 3.64$ & PDPN & Podoplanin \\
\hline 51 & $\downarrow 3.04$ & SLC11A1 & Natural resistance-associated macrophage protein 1 \\
\hline 52 & $\downarrow 3.08$ & SLC46A2 & Thymic stromal cotransporter homolog \\
\hline 53 & $\downarrow 4.09$ & SLC8A1 & Sodium/calcium exchanger 1 \\
\hline 54 & $\downarrow 3.15$ & TLR2 & Toll-like receptor 2 \\
\hline
\end{tabular}

The list of up- $(\uparrow)$ and down- $(\downarrow)$ regulated genes in macrophages grown as co-culture with canine mammary cancer cells. The unpaired $t$-test with BenjaminHochberg FDR $<5 \%$ (false discovery rate) correction (with $p$ value cut-off < 0.01 ) (Gene Spring, Agilent, USA) and further PANTHER analysis were conducted

IHC analysis also confirmed acquisition of macrophage's marker by cancer cells after co-culture. The expression of CSF-1R antigen was significantly higher ( $\mathrm{p}$ $<0.05$ ) in all the cancer cell lines after co-culturing with macrophages (Figure 6, Table 7). Thus, the co-culture conditions induced or increased macrophage antigens expression by cancer cells.

\section{Migration assay}

The wound healing assay showed that in all of the cancer cell lines the co-culturing with macrophages increased their migratory abilities (Figure 7). CMT-U27 cells grown with macrophages completely closed the wound $(100 \%)$ in 6 hrs, whereas CMT-U27 control cells after 6 hrs closed 71.5\% of the wound. Similarly, CMTU309 and P114 cells (grown with macrophages) after 6 hrs almost completely closed the wound $(99.2 \%$ and
99.9\%, respectively), whereas control cells closed only $49 \%$ and $54 \%$ (respectively) of the wound. CMT-W1 cells grown with macrophages completely closed the wound after $4 \mathrm{hrs}$, whereas CMT-W1 control cells after 6 hrs (after 4 hrs $64 \%$ of the wound was closed). CMTW2 cells grown with macrophages closed $80 \%$ of the wound after $6 \mathrm{hrs}$, whereas control cells closed only $52 \%$ of the wound.

\section{Invasion assay and 3D culture}

Invasion assay showed that not all of the cancer cells have migratory abilities. Only CMT-W1 and CMT-W2 control cells migrated throw the Matrigel (Figure 8A, B). The co-culturing of these cells for $72 \mathrm{hrs}$ with macrophages significantly increased their migratory abilities (Figure 8A, B). The fluorescence intensity related to the CMT-W1 control cells migration was 17.57 , whereas

Table 4 Genes involved in over-manfested cellular pathways in canine mammary cancer cells grown as a co-culture with macrophages

\begin{tabular}{lll}
\hline Pathway & number of genes & P-value \\
\hline Inflammation mediated by chemokine and cytokine signaling pathway & 21 & $1.81 \mathrm{E}-11$ \\
\hline Toll receptor signaling pathway & 7 & $9.44 \mathrm{E}-06$ \\
\hline B cell activation & 7 & $6.80 \mathrm{E}-05$ \\
\hline Purine metabolism & 3 & $1.04 \mathrm{E}-04$ \\
\hline T cell activation & 8 & $1.60 \mathrm{E}-04$ \\
\hline Acetate utilization & 2 & $6.87 \mathrm{E}-04$ \\
\hline Apoptosis signaling pathway & $3.86 \mathrm{E}-03$ \\
\hline Adenine and hypoxanthine salvage pathway & $8.65 \mathrm{E}-03$ \\
\hline Interleukin signaling pathway & $8.68 \mathrm{E}-03$ \\
\hline Plasminogen activating cascade & 2 & $1.19 \mathrm{E}-02$ \\
\hline 5-Hydroxytryptamine degredation & 6 & $2.19 \mathrm{E}-02$ \\
\hline Lysine biosynthesis & 2 & $2.48 \mathrm{E}-02$ \\
\hline Salvage pyrimidine deoxyribonucleotides & 2 & $3.69 \mathrm{E}-02$ \\
\hline PDGF signaling pathway & 1 & $3.99 \mathrm{E}-02$ \\
\hline Methylcitrate cycle & 1 & $4.89 \mathrm{E}-02$
\end{tabular}

The list of over-manifested cellular PANTHER pathways in cancer cells grown as co-cultures with macrophages. The binomial test for each PANTHER pathway was used 
Table 5 Genes involved in over-manifested cellular pathways in macrophages grown as a co-culture with canine mammary cancer cells

\begin{tabular}{lll}
\hline Pathway & number of genes & P-value \\
\hline Angiogenesis & 13 & $1.17 \mathrm{E}-04$ \\
\hline p53 pathway feedback loops 2 & 6 & $2.16 \mathrm{E}-04$ \\
\hline Wnt signaling pathway & 17 & $2.90 \mathrm{E}-04$ \\
\hline Alzheimer disease-presenilin pathway & 9 & $1.04 \mathrm{E}-03$ \\
\hline Cadherin signaling pathway & 9 & $1.55 \mathrm{E}-03$ \\
\hline p53 pathway & 8 & $1.63 \mathrm{E}-03$ \\
\hline Plasminogen activating cascade & $2.84 \mathrm{E}-03$ \\
\hline TGF-beta signaling pathway & $5.07 \mathrm{E}-03$ \\
\hline Inflammation mediated by chemokine and cytokine signaling pathway & $9.09 \mathrm{E}-03$ \\
\hline Arginine biosynthesis & 3 & $1.29 \mathrm{E}-02$ \\
\hline Alzheimer disease-amyloid secretase pathway & 8 & $1.77 \mathrm{E}-02$ \\
\hline Alpha adrenergic receptor signaling pathway & 12 & $2.68 \mathrm{E}-02$ \\
\hline Metabotropic glutamate receptor group I pathway & 2 & $3.95 \mathrm{E}-02$ \\
\hline FGF signaling pathway & 5 & $4.05 \mathrm{E}-02$ \\
\hline Succinate to proprionate conversion & 3 & $4.16 \mathrm{E}-02$ \\
\hline PLP biosynthesis & 3 & $4.16 \mathrm{E}-02$ \\
\hline Endothelin signaling pathway & 6 & $4.29 \mathrm{E}-02$ \\
\hline Muscarinic acetylcholine receptor 1 and 3 signaling pathway & $4.67 \mathrm{E}-02$ \\
\hline
\end{tabular}

The list of over-manifested cellular PANTHER pathways in macrophages grown as co-cultures with canine mammary cancer cells. The binomial test for each PANTHER pathway was used

to the CMT-W1 cell line grown with macrophages was $38.08(\mathrm{p}<0.001)$. The fluorescence intensity related to the CMT-W2 control cells migration was 38.00, whereas to the CMT-W2 cell line grown with macrophages was $80.75(\mathrm{p}<0.05)$.

To confirm the ability of these cell lines to matrix invasion, we have assessed their growth characteristics on Matrigel matrix (Figure 8C). After $22 \mathrm{hrs}$ of culturing (similarly as in the invasion assay) on Matrigel CMTU27, CMT-U309 and P114 cell lines formed colonies, whereas CMT-W1 and CMT-W2 cell lines formed branching structures (Figure $8 \mathrm{C}$ ) what indicated their invasive phenotype. The culture was maintained for 1 week, showing that after 5 days also P114 cell line formed slight branches.

\section{Discussion}

It has been evident over the last few years that macrophages play an important role (via various factors) in tumour cell invasion of the normal surrounding tissues, cancer proliferation and metastasis to local and distant sites [19]. All the interactions within the tumour are

Table 6 Fold change of genes randomly selected for confirmation of microarray results

\begin{tabular}{|c|c|c|c|c|c|c|c|c|c|}
\hline & Wnt7b & IL18 & CCL2 & CCL3 & CD163 & CSF1R & HIF1 & MMP9 & VEGF-C \\
\hline MQ co-culture with CMT-U27 v.s. monoculture & $\uparrow 2.08$ & $\downarrow 111.1$ & $\downarrow 58.8$ & & & & & & \\
\hline MQ co-culture with CMT-U309 v.s. monoculture & $\uparrow 2.27$ & $\downarrow 1.5$ & $\downarrow 9.1$ & & & & & & \\
\hline MQ co-culture with P114 v.s. monoculture & $\uparrow 1.45$ & $\downarrow 6.3$ & $\downarrow 8.3$ & & & & & & \\
\hline MQ co-culture with CMT-W1 v.s. monoculture & $\uparrow 6.67$ & $\downarrow 142.9$ & $\downarrow 22.7$ & & & & & & \\
\hline MQ co-culture with CMT-W2 v.s. monoculture & $\uparrow 1.61$ & $\downarrow 62.5$ & $\downarrow 13.3$ & & & & & & \\
\hline CMT-U27 co-culture with MQ v.s. monoculture & & & $\uparrow 407.3$ & $\uparrow 1.93$ & $\uparrow 58.08$ & $\uparrow 229.9$ & $\uparrow 9.1$ & $\uparrow 711.6$ & $\uparrow 28.1$ \\
\hline CMT-U309 co-culture with MQ v.s. monoculture & & & $\uparrow 1612.4$ & $\uparrow 1.01$ & $\uparrow 48.67$ & $\uparrow 129.8$ & $\uparrow 1.4$ & $\uparrow 207.9$ & $\uparrow 1.2$ \\
\hline P114 co-culture with MQ v.s. monoculture & & & $\uparrow 931.0$ & $\uparrow 1269.46$ & $\uparrow 17.99$ & $\uparrow 64.1$ & $\uparrow 1.7$ & $\uparrow 71.3$ & $\uparrow 1.9$ \\
\hline CMT-W1 co-culture with MQ v.s. monoculture & & & $\uparrow 333.8$ & $\uparrow 101.13$ & $\uparrow 11.87$ & $\uparrow 9.3$ & $\uparrow 3.0$ & $\uparrow 209.8$ & $\uparrow 7.7$ \\
\hline CMT-W2 co-culture with MQ v.s. monoculture & & & $\uparrow 109.9$ & $\uparrow 51.09$ & $\uparrow 31.25$ & $\uparrow 8.3$ & $\uparrow 5.0$ & $\uparrow 147.3$ & $\uparrow 30.4$ \\
\hline
\end{tabular}

Fold change of genes randomly selected for confirmation of microarray results in macrophages grown as a co-culture with canine mammary cancer cell lines (versus macrophages grown as a monoculture) and in canine mammary cancer cell lines grown as a co-culture with macrophages (versus canine mammary cancer cell lines grown as a monoculture) 


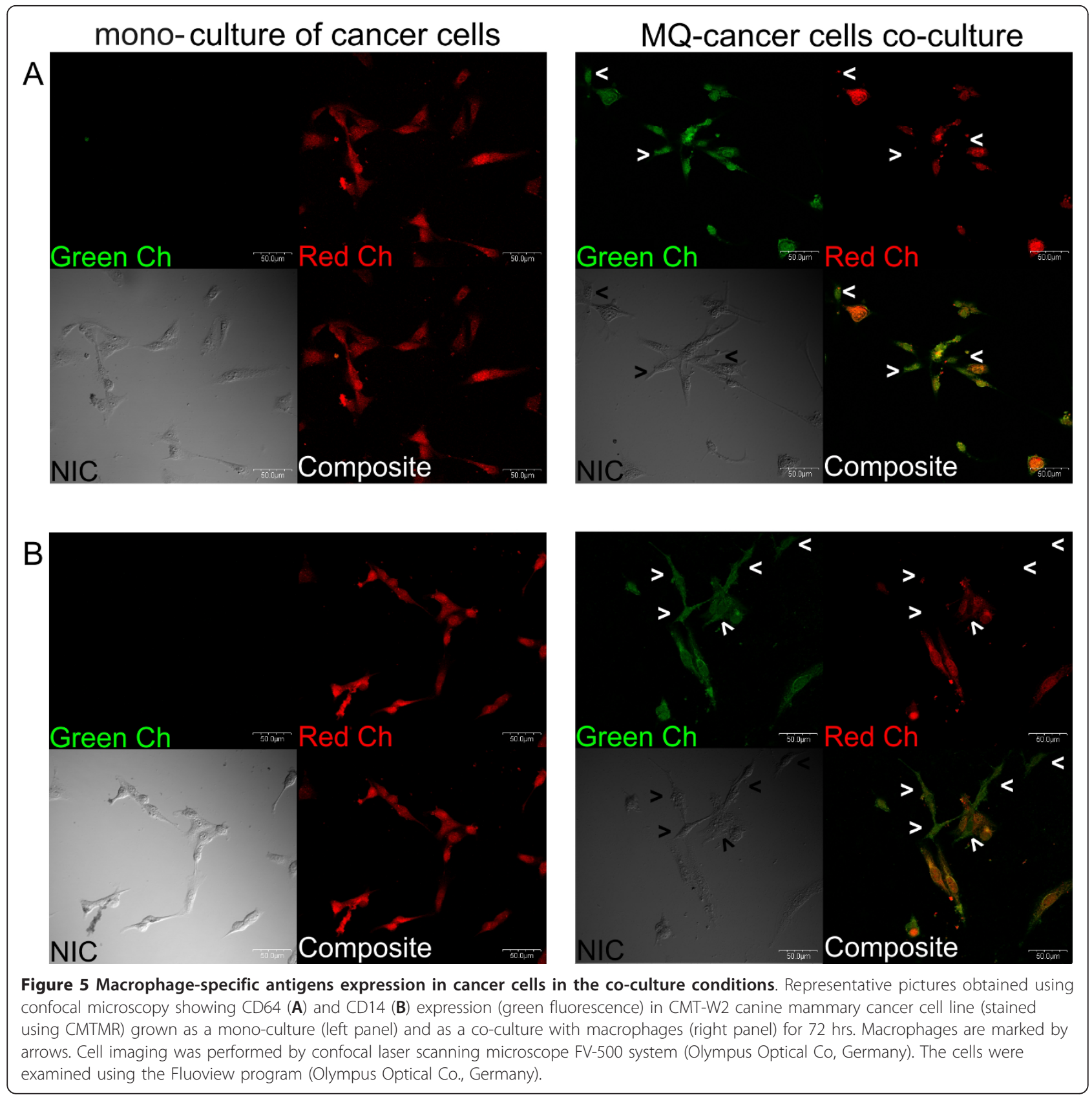

intricately complex and a better understanding of them would require some further exploration of the underlying molecular processes.

In this article, we demonstrated that co-culturing of canine mammary cancer cells and macrophages initiate a dynamic 'chemical conversation' between the tumour cells and macrophages. They also start to behave as one organism. Many of the previous studies have been conducted using cancer cells and macrophages grown without direct contact in trans-well inserts or modified Boyden chambers [10], however there are also very few reports on direct co-culturing of macrophages and cancer cells [20-22]. Despite that direct co-culturing of macrophages and cancer cells (with cell-cell contact) can be a good experimental model, because it reflects in vivo conditions more vividly (where all the cells have direct contact) than co-culturing where the cells can contact via soluble factors only, direct co-culturing brings about the risk of macrophages contamination by cancer cells owing to macrophages taking up fragments of cancer cells. To assess the possible risk of artificial sorting of macrophages (that digested red-stained cancer 
A.

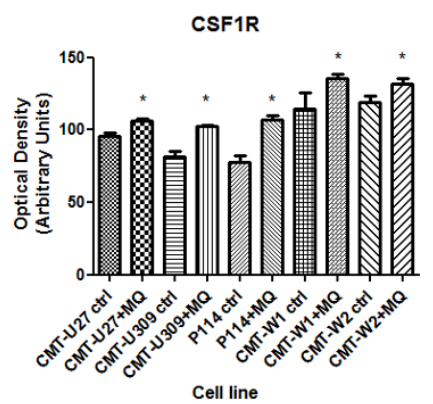

B.

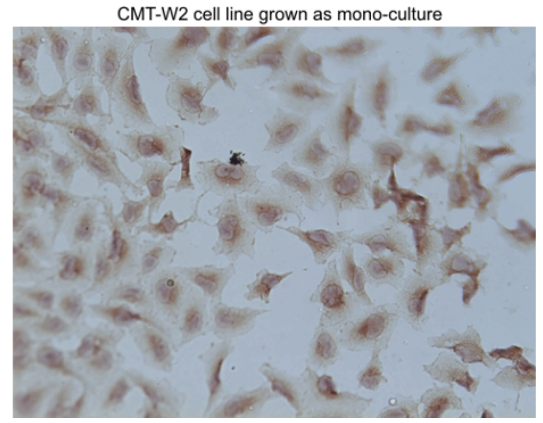

CMT-W2 cell line grown as co-culture with macrophages

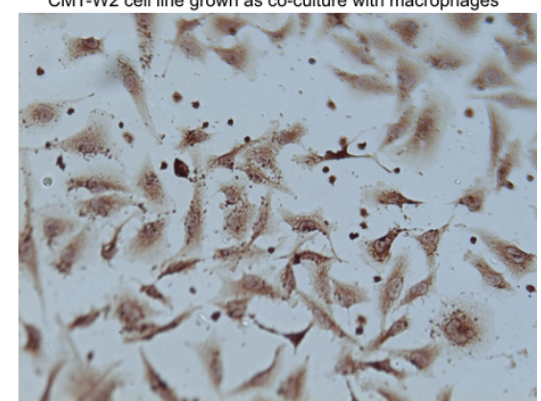

Figure 6 CSF1R expression in canine mammary cancer cell lines in control conditions and after the co-culture with macrophages. (A) The graph of mean optical density of CSF1R (and SD) in canine mammary cell lines (CMT-U27, CMT-U309, P114, CMT-W1 and CMT-W2) grown in control conditions (Ctrl) and as a co-culture with macrophages (+MQ). (B) Representative pictures of CSF1R expression in CMT-W2 cell line (in control conditions and after co-culture with macrophages) obtained using Olympus BX60 microscope (at the magnification of 200X). The CSF1R is reflected as brown colour. Ten pictures in each slide were analyzed. The colorimetric intensity of the IHC-stained antigen spots was counted by a computer-assisted image analyzer (Olympus Microimage ${ }^{\mathbf{T M}}$ Image Analysis, software version 4.0 for Windows, USA) and the antigen spot colour intensity is expressed as mean pixel optical density on a 1-256 scale. The statistical analysis was performed using Prism version 5.00 software (GraphPad Software, USA). The unpaired $t$-test was applied to analyze the optical density in cell lines. $p<0.05$ was regarded as significant and marked as *.

cells) as cancer cells (CMTMR-positive group) we checked our post-sort population using fluorescence microscopy (no red-stained cells in macrophages tube and no unstained cells in cancer cells tube have been seen, data not shown). Our co-culture has also been assessed using confocal microscopy (Figures 5 and 9). It showed that cancer cells were perfectly bright stained with CMTMR (whole cytoplasms was regularly redstained). These cells also showed green-stained pattern due to the macrophages-specific antigen expression. Thus, we confirmed that we sorted the population of cancer cells showing macrophages-specific antigens. We have also observed very few macrophages with very small amount of red dye in their phagosomes which probably were digested fragments of cancer cells (Figure 9), but we observed attentively only the macrophages without any red dye. During cell sorting we only took cells with high PerCP-Area red-signal (Figure 1F) and gated for sorting only the high-positive cancer cells as opposed to macrophages with low signal. Even if some macrophages happen to have red dye in phagosome, they would have been somewhere between these two gates or qualified as macrophages. Bearing in mind that the possibility of contamination of macrophages RNA samples by cancer RNA is even less, as macrophages produce ribonucleases [23] that immediately degrade any digested (unstable) RNA molecules. Moreover, the possibility that macrophages can take up cancer cells during in vitro culturing is as likely as in a naturally occurring tumour in vivo, but researchers run a risk because the problem is extremely interesting and requires investigation $[24,25]$.

The present microarray analysis of five various canine mammary cancer cell lines and canine macrophages grown together, revealed significant changes in genes expression in comparison to the same cells grown as mono-cultures.

Under co-culture conditions the cancer cells express the macrophages-specific antigens, e.g. CD14, CD64, CD163, CSF1R (Table 3, Figures 5, 6 and 9). According to subject literature, CD163 is expressed not only by normal monocytes/macrophages but also by neoplasms $[26,27]$. CD163-positive cancers had more severe histological aberrations due to genomic instability. Thus, it is hypothesized [26] that tumour cells express atypical genes (specific for macrophages) due to genomic instability. This may be caused by the presence of various proteins secreted by macrophages and changes induced by them on the microenvironment. Another theory explaining why cancer cells may exhibit myeloid

Table 7 CSF1R expression at protein level in canine mammary cancer cell lines

\begin{tabular}{ccccccccccc}
\hline Cell line & $\begin{array}{c}\text { CMT-U27 } \\
\text { ctrl }\end{array}$ & $\begin{array}{c}\text { CMT-U27 } \\
\text { +MQ }\end{array}$ & $\begin{array}{c}\text { CMT-U309 } \\
\text { ctrl }\end{array}$ & $\begin{array}{c}\text { CMT-U309 } \\
+ \text { +MQ }\end{array}$ & $\begin{array}{c}\text { P114 } \\
\text { ctrl }\end{array}$ & $\begin{array}{c}\text { P114 } \\
\text { +MQ }\end{array}$ & $\begin{array}{c}\text { CMT-W1 } \\
\text { ctrl }\end{array}$ & $\begin{array}{c}\text { CMT-W1 } \\
+ \text { +MQ }\end{array}$ & $\begin{array}{c}\text { CMT-W2 } \\
\text { ctrl }\end{array}$ & $\begin{array}{c}\text { CMT-W2 } \\
+ \text { +MQ }\end{array}$ \\
\hline $\begin{array}{c}\text { Mean Optical Density } \\
\text { (Arbitrary Units) }\end{array}$ & 95.40 & 106.60 & 81.28 & 102.30 & 77.99 & 107.20 & 114.50 & 135.40 & 119.10 & 132.00 \\
\hline SD & 4.99 & 2.23 & 5.59 & 1.35 & 5.82 & 4.12 & 15.77 & 4.86 & 6.34 & 4.87 \\
\hline
\end{tabular}

The CSF1R expression in canine mammary cancer cell lines grown as mono-culture (ctrl) and as co-culture with macrophages (+MQ). Results are presented as mean optical density \pm SD 


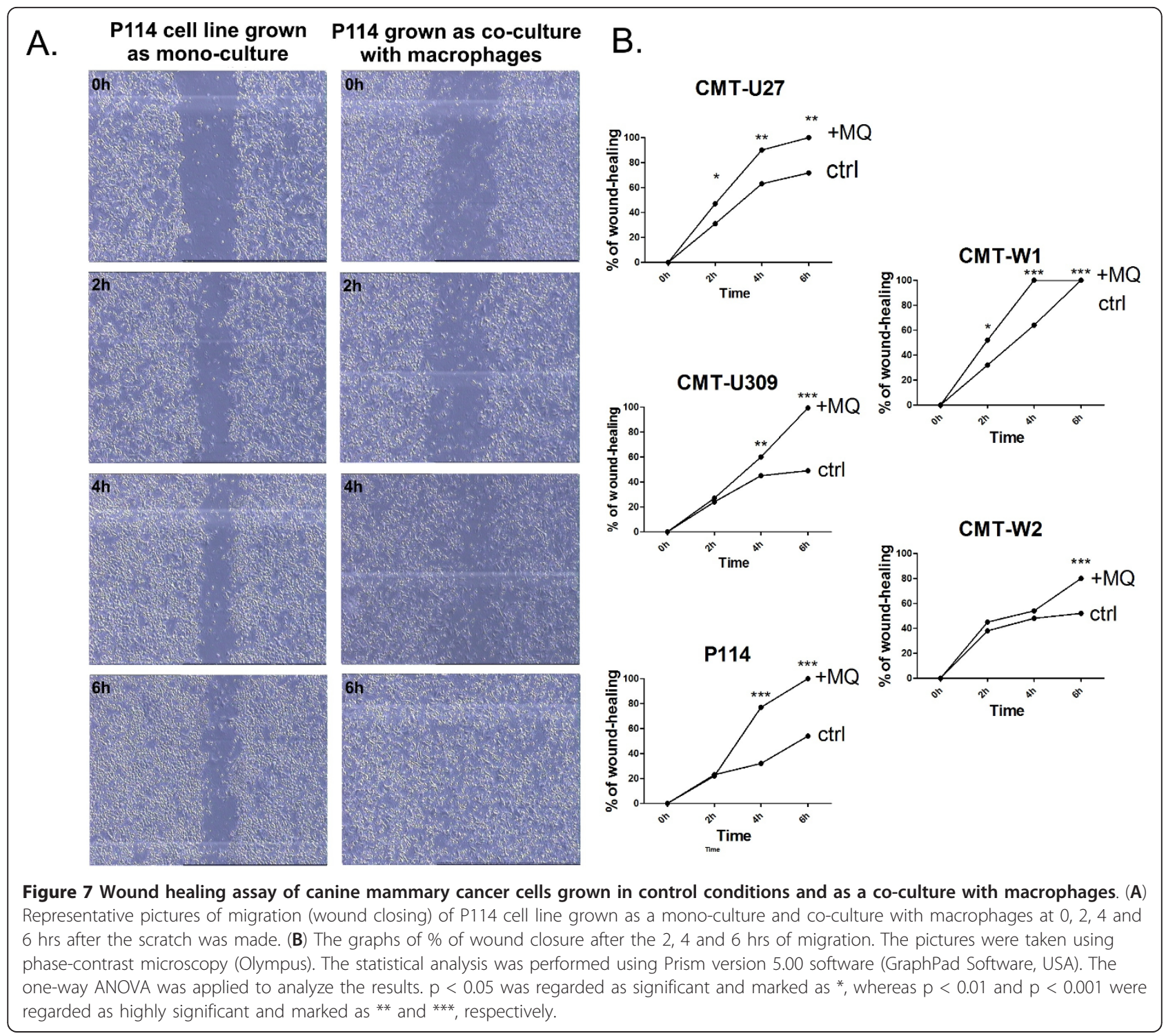

cells-specific antigens is that the cells fuse, forming hybrids that adopt phenotypic features of both parental cells [28]. Cancer cells may fuse spontaneously with several types of somatic cells [29-32]. Some authors suggest that the result of cancer-myeloid cell fusion is the hybrid with a metastatic phenotype [33-39]. The tumour cells that express myeloid antigens may also exhibit other phenotypic characteristics of macrophages, such as capabilities of cell rolling, spreading, dissociation, diapedesis, migration and matrix invasion. The metastatic cancer cells have all these capacities because the process of metastasis requires a coordinated steps promoting angiogenesis, controlling adhesion, proteolysis and motility. Our confocal imaging and IHC examination has proven that under co-culture conditions expression of macrophages markers (CD14, CD64, CSF1R) in almost all of the cancer cells was initiated. Moreover, migration and invasion assays showed that the presence of macrophages in cancer microenvironment triggers migration in all of the cancer cell lines. The co-culturing of macrophages increased invasion in the cell lines that show high invasive abilities in control conditions. The ability of CD163 receptor (and perhaps other macrophage-specific antigens) to trigger the production of pro-inflammatory mediators $[40,41]$ may be a key factor that brings changes to the cancer cell biology and stimulates it to cytokines/chemokines/growth factors production for further myeloid cell attraction.

Our microarray analysis of cancer cells grown with macrophages revealed the over-manifestation of genes activity which are involved in macrophages-cancer cells 'conversation'. We found up-regulation of the highly potent 


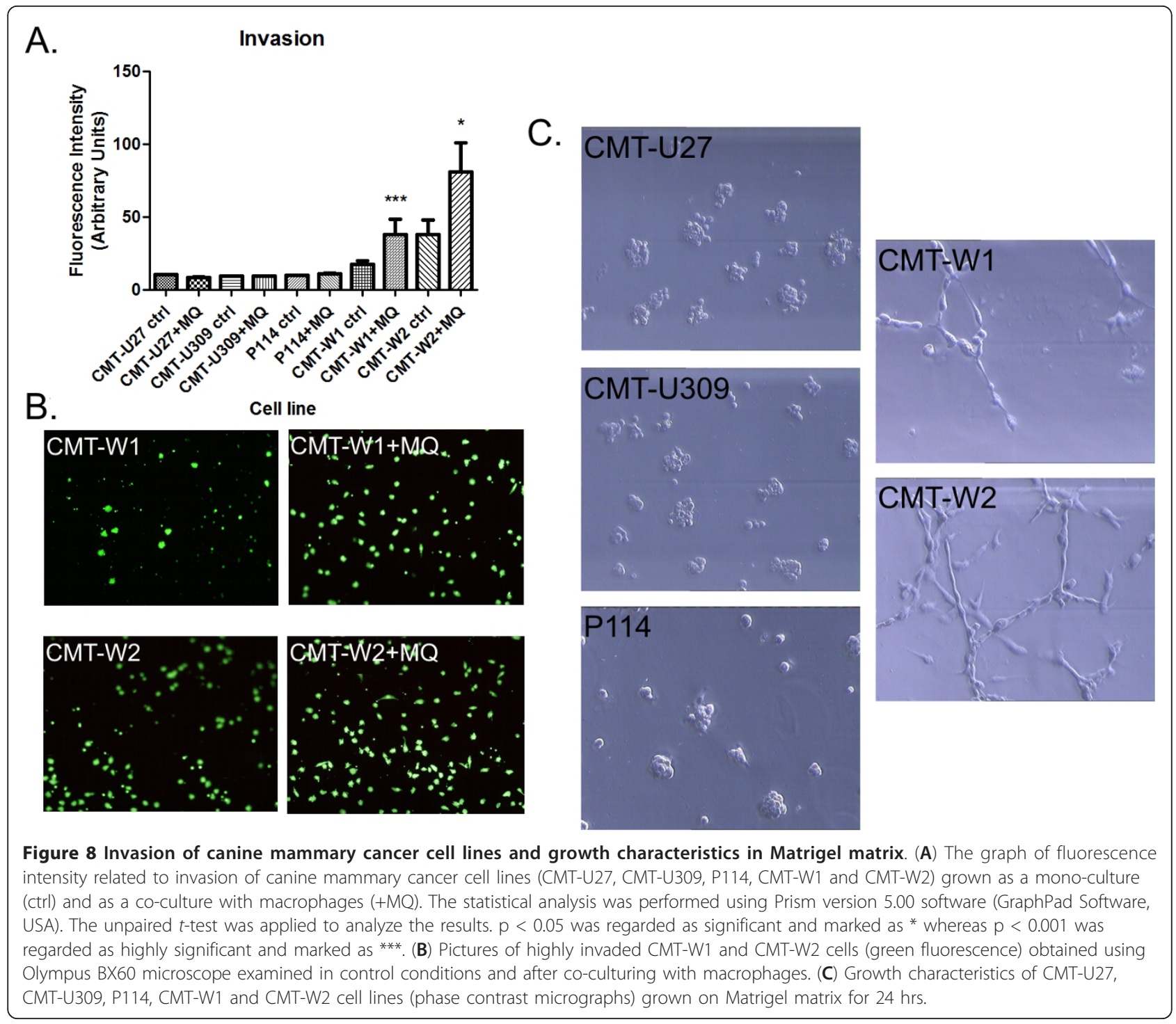

macrophage attracting factors: CCL2 (MCP-1), CCL3 (MIP-1 $\alpha$ ), CCL4 (MIP-1 $\beta$ ) and CCL5 (RANTES) as well as CCR5 in cancer cells grown as co-culture with macrophages. Recent studies have demonstrated that CCL2 acts directly (via CCR5) in an autocrine manner on several human carcinomas regulating the migration and invasive properties of tumour cells $[42,43]$. Furthermore, CCL3CCR5 axis can increase the MMP-9 expression contributing to angiogenesis, ECM degradation and metastasis. Our gene expression analysis seems to support both hypotheses, as besides CCL2, CCL3 and CCR5 up-regulation, we also observed increased expression of MMP-9 in cancer cells grown under co-culture conditions with macrophages.

We found down-regulation of the pro-inflammatory CD163 in macrophages grown as co-culture with cancer cells. We also found down-regulation of several key inflammation cytokines and macrophage activators, such as: CCL2, CCL13, CCR1, and CCR5; whereas up-regulation of other inflammation cytokines: CXCL10, CSF-2. Decrease of the expression of these genes in macrophages grown with cancer cells as co-cultures may be induced by hypoxia. Down-regulation of CCL2, CCR1 and CCR5 genes in macrophages under hypoxic conditions has been demonstrated by various authors [44-46]. This phenomenon has a biological explanation, as decrease of CCL2, CCR1 and CCR5 expression inhibits chemotaxis signalling what in turn prevents TAMs from leaving hypoxic areas [47] and triggers their angiogenic effect (e.g. by CXCL10 chemokine). Up-regulation of HIF-1 in cancer cells may indicate hypoxic conditions in co-culture (similarly as in tumour). Hypoxia additionally regulates angiogenesis by up-regulating VEGF-C in cancer cells and it initiates their epithelial-mesenchymal transition (EMT) [48]. 


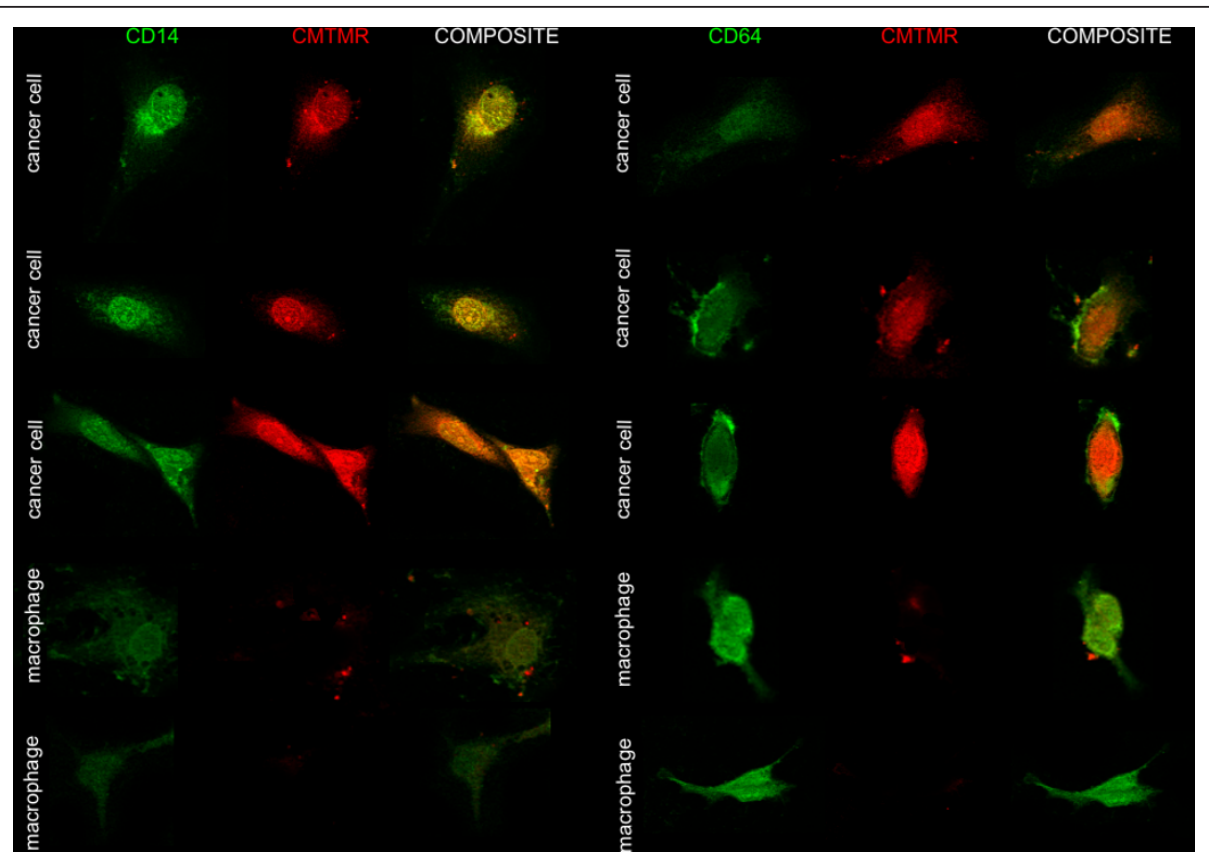

Figure 9 Co-cultured cells staining characteristics. Pictures of representative cells (canine mammary cancer cells and macrophages) obtained using confocal microscopy showing CD14 and CD64 expression (green fluorescence) and red-stained cytoplasms of cancer cells (stained using CMTMR) grown as a co-culture for $72 \mathrm{hrs}$. Cell imaging was performed by confocal laser scanning microscope FV-500 system (Olympus Optical Co, Germany). The cells were examined using the Fluoview program (Olympus Optical Co., Germany).

Our gene expression analysis also revealed up-regulation of CSF-2 (GM-CSF) in macrophages grown as coculture with cancer cells and CSF-2, CSF-3 and CSF1R up-regulation in cancer cells grown together with macrophages. CSFs are potent factors regulating the survival and differentiation of macrophages being their chemoattractants [49]. The CSF-1R expression in normal mice and humans is limited to macrophages [49]. However, in many tumours CSF-1R and CSFs are also expressed in cancer cells. CSF-1R expression at protein level was also confirmed in this study (Figure 6). For example, co-expression of CSF-1 and its receptor can be found in $50 \%$ of late stage breast and $70 \%$ of endometrial cancers [50,51]. During the course of our previous studies we found the CSF-1R expression in canine mammary cancer cells (Figure 10), as well as in tumour-associated macrophages [52]. The results of the studies of Kirma et al. [53] suggest that the CSFs might have an autocrine role through CSF1R in epithelial tumour cells promoting their invasiveness into the surrounding matrix $[54,55]$.

All genes given above are important to entrap macrophages in malignant tumours [56].

In macrophages grown as co-culture with cancer cells expression of three ligands of Wnt pathway increased significantly: Wnt5b, Wnt7a and Wnt7b. Although the Wnt activation has been described by many authors in various cancer cells $[57,58]$, only one study, so far [5], described the Wnt activation in macrophages taken from mice tumours. The authors described mechanism, by which macrophages stimulate Wnt signalling pathway in vascular endothelial cells by Wnt7b. This signalling cascade eventually results in the vascular remodelling. Thus, the new hypothesis is proposed, that the subpopulation of macrophages, modulating Wnt-signalling is located along the tumour vasculature to regulate endothelial cells proliferation and apoptosis [5].

\section{Conclusions}

Based on the results of hereby study and the available literature we conclude that the presence of macrophages in the cancer environment induces expression of macrophage-specific antigens in cancer cells. It may be caused by macrophage-cancer cell fusion or may be induced by chemokines. This macrophage-specific gene expression induces production of the pro-inflammatory mediators by cancer cells, that stimulate not only further monocytes recruitment from blood vessels and their differentiation into adult macrophages, but also cancer migration and angiogenesis (Figure 11). Moreover, we have showed that the presence of macrophages increases cancer cells migration and invasion. Thus, we suppose that gaining the macrophages phenotype by cancer cells constitutes one of the most important elements that increase their possibility to metastasize. Moreover, the 'cross-talk' between these cells leads to up-regulation of 

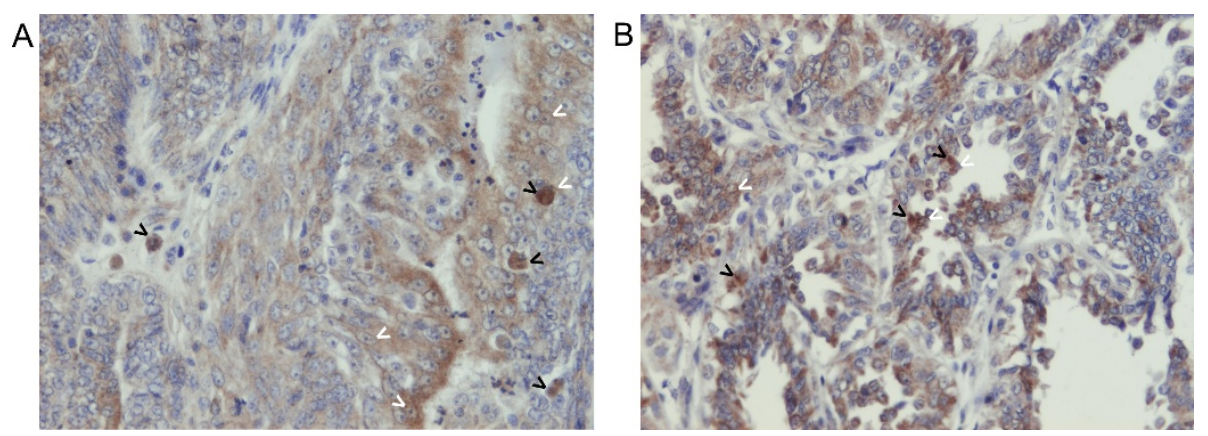

Figure 10 The expression of CSF1R and CD14 in canine mammary cancer tissues. Pictures obtained using Olympus BX60 microscope (x200) showing CSF1R (A) and CD14 (B) expression in canine mammary cancer tissues. These macrophage-specific antigens were detected not only on the monocytes/macrophages, but also on the cancer tissue (reflected as brown colour). Black arrows indicate macrophages, whereas white arrows indicate brown-coloured cancer cells. Tissue sections were stained using rabbit polyclonal CSF1R antibody and rabbit polyclonal CD14 antibody (both obtained from Abcam, United Kingdom). For the staining the EnVision kit (Dako, Denmark) was used (Labelled Polymers consist of secondary anti-rabbit antibodies conjugated with the Horseradish peroxidase HRP enzyme complex). To develop the coloured product, the 3,3'-Diaminobenzidine (DAB) substrate was used. Finally, the haematoxylin was used for nuclei counterstaining. The tissue details, procedure, and results have been described previously [20].

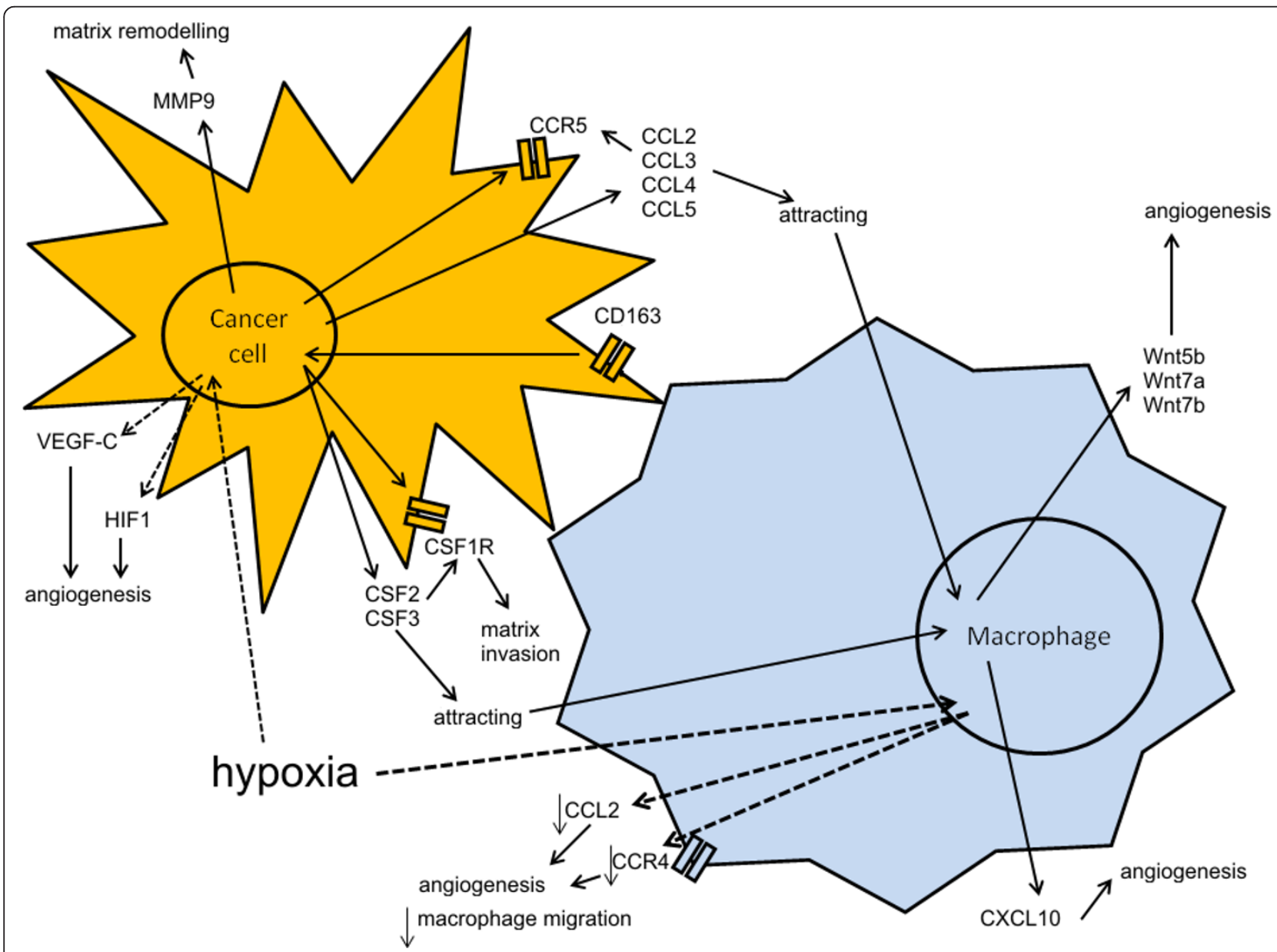

Figure 11 Scheme of possible interactions between cancer cells and macrophages. The scheme of possible interactions between the up/ down-regulated genes in canine mammary cancer cell lines and macrophages. Abbreviations: CCL2, C-C motif chemokine 2; CCL3, C-C motif chemokine 3; CCL4, C-C motif chemokine 4; CCL5, C-C motif chemokine 5; CCR4, C-C chemokine receptor 4; CCR5, C-C chemokine receptor 5; CSF2 \& CSF3, Colony stimulating factor $2 \& 3$; CXCL10, C-X-C motif chemokine 10; HIF1, Hypoxia inducible factor 1; MMP9, Matrix metalloproteinase-9. 
Wnt genes in macrophages increasing new vessels formation.

\section{Acknowledgements}

This work was supported by grant no N N308012939 from the Ministry of Sciences and Higher Education. This work was performed owing to financial support of the Foundation for Polish Science (Start stipendium and ParentBridge program).

\section{Author details}

${ }^{1}$ Department of Physiological Sciences, Faculty of Veterinary Medicine, Warsaw University of Life Sciences - WULS, Nowoursynowska 159, 02-776 Warsaw, Poland. ${ }^{2}$ Department of Animal Environment Biology, Faculty of Animal Sciences, Warsaw University of Life Sciences - WULS, Ciszewskiego 8, 02-786 Warsaw, Poland.

\section{Authors' contributions}

MK research design, experimental design, FACS analyses and cell sorting, migration assay, manuscript and figures preparation, KP microarray analyses, real-time $\mathrm{APCR}$ experiments, KM invasion assay, immunohistochemistry, MG confocal microscopy analyses, 3D culture, AM microarray analyses, TM manuscript preparation. All authors read and approved the final manuscript.

\section{Competing interests}

The authors declare that they have no competing interests.

Received: 28 July 2011 Accepted: 21 February 2012

Published: 21 February 2012

\section{References}

1. Hagemann T, Wilson J, Burke F, Kulbe H, Li NF, Pluddemann A, Charles K, Gordon S, Balkwill FR: Ovarian cancer cells polarize macrophages toward a tumor-associated phenotype. J Immunol 2006, 176:5023-5032.

2. Pollard JW: Tumour-educated macrophages promote tumour progression and metastasis. Nat Rev Cancer 2004, 4:71-78.

3. Smith HO, Anderson PS, Kuo DY, Goldberg GL, DeVictoria CL, Boocock CA, Jones JG, Runowicz CD, Stanley ER, Pollard JW: The role of colonystimulating factor 1 and its receptor in the etiopathogenesis of endometrial adenocarcinoma. Clin Cancer Res 1995, 1:313-325.

4. Duff MD, Mestre J, Maddali S, Yan ZP, Stapleton P, Daly JM: Analysis of gene expression in the tumor-associated macrophage. J Surg Res 2007, 142(1):119-128.

5. Oljavo LS, Whittaker CA, Condeelis JS, Pollard JW: Gene expression analysis of macrophages that facilitate tumor invasion supports a role for Wntsignaling in mediating their activity in primary mammary tumors. $J$ Immunol 2010, 184:702-712.

6. Król M, Pawłowski KM, Skierski J, Rao NAS, Hellmen E, Mol JA, Motyl T: Transcriptomic profile of two canine mammary cancer cell lines with different proliferative and anti-apoptotic potential. J Physiol Pharmacol 2009, 60:95-106.

7. Król M, Pawłowski KM, Skierski J, Turowski P, Majewska A, Polańska J, Ugorski M, Morty RE, Motyl T: Transcriptomic "portraits" of canine mammary cancer cell lines with various phenotype. J App/ Genet 2010, 51:169-183.

8. Król M, Polańska J, Pawłowski KM, Skierski J, Majewska A, Ugorski M, Motyl T: Molecular signature of cell lines isolated from mammary adenocarcinoma metastases to lungs. J Appl Genet 2010, 51:37-50.

9. Pawłowski KM, Popielarz D, Szyszko K, Motyl T, Król M: Growth Hormone Receptor RNA interference decreases proliferation and enhances apoptosis in canine mammary carcinoma cell line CMT-U27. Vet Comp Oncol 2012, 10(1):2-15.

10. Hagemann T, Robinson SC, Schulz M, Trumper L, Balkwill FR, Binder C: Enhanced invasiveness of breast cancer cell lines upon co-cultivation with macrophages is due to TNF-a dependent up-regulation of matrix metalloproteases. Carcinogenesis 2004, 28:1543-1549.

11. Martinez FO, Gordon S, Locati M, Mantovani A: Transcriptional profiling of the human monocyte-to-macrophage differentiation and polatization: new moleculaes and patterns of gene expression. J Immunol 2006, 177:7303-7311.
12. Mi H, Lazareva-Ulitsky B, Loo R, Kejariwal A, Vandergriff J, Rabkin S, Guo N, Muruganujan A, Doremieux O, Campbell MJ, Kitano H, Thomas PD: The PANTHER database of protein families, subfamilies, functions and pathways. Nucleic Acids Res 2005, 33:D284-D288.

13. Brinkhof B, Spee B, Rothuizen J, Penning LC: Development and evaluation of canine reference genes for accurate quantification of gene expression. Anal Biochem 2006, 356:36-43.

14. Etschmann B, Wilcken B, Stoevesand K, von der Schulenburg A, SternerKock $A$ : Selection of reference genes for quantitative real-time PCR analysis in canine mammary tumors using the GeNorm algorithm. Vet Pathol 2006, 43:934-942.

15. Schmittgen TD, Livak K: Analyzing real-time PCR data by the comparative Ct method. Nat Prot 2008, 3:1101-1108.

16. Rodriguez LG, Wu X, Guan JL: Wound-healing assay. Methods Mol Biol 2005, 294:23-29.

17. Olumi AF, Grossfeld GD, Hayward SW, Carroll PR, Tlsty TD, Cunha GR: Carcinoma-associated fibroblasts direct tumor progression of initiated human prostatic epithelium. Cancer Res 1999, 59:5002-5011.

18. Ohishi K, Vernum-Finney B, Serda RE, Anasetti C, Bernstein ID: The Notch ligand, Delta-1, inhibits the differentiation of monocytes into macrophages but permits their differentiation into dendritic cells. Blood 2001, 98:1401-1407.

19. Lewis CE, Pollard JW: Distinct role of macrophages in different tumor microenvionments. Cancer Res 2006, 66(2):605-612.

20. Green CE, Liu T, Montel V, Hsiao G, Lester RD, Subramaniam S, Gonias SL, Klemke RL: Chemoattractant signaling between tumor cells and macrophages regulates cancer cell migration, metastasis and neovascularization. PLoS One 2009, 4:e6713.

21. Guimaraes FSF, Abud APR, Oliveira SM, Oliveira CC, Cesar B, Andrade LF, Donatti L, Gabardo J, Trindade EST, Buchi DF: Stimulation of lymphocyte anti-melanoma activity by co-cultured macrophages activated by complex homeopathic mediciation. BMC Cancer 2009, 9:293.

22. Abraham D, Zins K, Sioud M, Lucas T, Schafer R, Stanley ER, Aharinejad S: Stromal cell-derived CSF-1 blockade prolongs xenograft survival of CSF1-negative neuroblastoma. Int J Cancer 2010, 126:1339-1352.

23. Lethinen $A$, Aho $S$, Kulonen E: Penetration of various mononuclear ribonucleases into rat experimental granulation-tissue fibroblasts and their intracellular affects. Hoppe Saylers Z Physiol Chem 1981, 362:1575-1582.

24. Bolpetti A, Silva JS, Villa LL, Lepique AP: Interleukin-10 production by tumor infiltrating macrophages plays a role in Human Papillomavirus 16 tumor growth. BMC Immunol 2010, 11:27.

25. Oljavo LS, King W, Cox D, Pollard JW: High-density gene expression analysis of tumor-associated macrophages from mouse mammary tumors. Am J Pathol 2009, 174:1048-1064.

26. Sabo I, Olsson H, Sun XF, Svanvik J: Expression of the macrophage antigen CD163 in rectal cancer cells is associated with early local recurrence and reduced survival time. Int J Canc 2009, 125:1826-1831.

27. Sabo I, Stal O, Olsson H, Dore S, Svanvik J: Breast cancer expression of CD163, a macrophage scavenger receptor, is related to Elary distant recurrence and reduced patient survival. Int J Cancer 2008, 123:780-786.

28. Powell AE, Anderson EC, Davies PS, Silk AD, Pelz C, Impey S, Wong MH: Fusion between intestinal epithelial cells and macrophages in a cancer context results in nuclear reprogramming. Cancer Res 2011, 71(4):1497-1505.

29. Jacobsen BM, Harrell JC, Jedlicka P, Borges VF, Varella-Garcia M, Horwitz KB: Spontaneous fusion with, and transformation of mouse stroma by, malignant human breast cancer epithelium. Cancer Res 2006, 66:8274-8279.

30. Liu C, Chen Z, Zhang T, Lu Y: Multiple tumor types may originate from bone marrow-derived cells. Neoplasia 2006, 8:716-724.

31. Nygren JM, Jovinge S, Breitbach M, Sawen P, Roll W, Hescheler J, Taneera J, Fleischmann BK, Jacobsen SE: Bone marrow-derived hematopoietic cells generate cardiomyocytes at a low frequency through cell fusion, but not transdifferentiation. Nat Med 2004, 10:494-501.

32. Su JL, Yen CJ, Chen PS, Chuang SE, Hong CC, Kuo IH, Chen HY, Hung MC, Kuo ML: The role of the VEGF-C/NEGFR-3 axis in cancer progression. Brit J Canc 2007, 96:541-545.

33. Chakraborty AK, Pawelek J, Ikeda Y, Miyoshi E, Kolesnikova N, Funasaka Y, Ichihashi M, Taniguchi N: Fusion hybrids with macrophage and 
melanoma cells up-regulate $\mathrm{N}$-acetylglucosaminyltransferase $\mathrm{V}$, beta1-6 branching, and metastasis. Cell Growth Differ 2001, 12:623-630.

34. Chakraborty AK, Pawelek JM: GnT-V, macrophage and cancer metastasis: a common link. Clin Exp Metastasis 2003, 20:365-373.

35. Chakraborty AK, Sodi S, Rachkovsky M, Kolesnikova N, Platt JT, Bolognia JL, Pawelek JM: A spontaneous murine melanoma lung metastasis comprised of host $x$ tumor hybrids. Cancer Res 2000, 60:2512-2519.

36. Pawelek JM, Chakraborty AK: Fusion of tumour cells with bone marrowderived cells: a unifying explanation for metastasis. Nat Rev Cancer 2008 8:377-386

37. Pawelek JM, Chakraborty AK: The cancer cell-leukocyte fusion theory of metastasis. Adv Cancer Res 2008, 101:397-444.

38. Pawelek JM: Cancer-cell fusion with migratory bone-marrow-derived cells as an explanation for metastasis: new therapeutic paradigms. Future Oncol 2008, 4:449-452.

39. Watkins SK, Li B, Richardson KS, Head K, Egilmez NK, Zeng Q, Suttles J Stout RD: Rapid release of cytoplasmic IL-15 from tumor associated macrophages is an initial and critical event in IL-12 initiated tumor regression. Eur J Immunol 2009, 39(8):2126-2135.

40. Fabriek BO, van Bruggen R, Deng DM, Ligtenberg AJM, Nazmi K, Schomagel K, Vloet RP, Dijkstra CD, van den Berg TK: The macrophage scavenger receptor CD163 functions as an innate immune sensor for bacteria. Blood 2009, 113:887-892.

41. van den Heuvel MM, Tensen CP, van As JH, van den Berg TK, Fluitsma DM, Dijkstra CD, Dopp EA, Droste A, van Gaalen FA, Sorg C, Hogger P, Beelen RHJ: Regulation of CD163 on human macrophages: cross-linking of CD163 induces signaling and activation. J Leukoc Biol 1999, 66:858-866.

42. Loberg RD, Day LL, Harwood J, Ying C, John LN, Giles R, Neeley CK, Pienta KJ: CCL2 is a potent regulator of prostate cancer cell migration and proliferation. Neoplasia 2006, 8:578-586.

43. Wu Y, Li YY, Matsushima K, Baba T, Mukida N: CCL3-CCR5 axis regulates intratumoral accumulation of leukocytes and fibroblasts and promotes angiogenesis in murine lung metastasis process. J Immunol 2008, 181:6384-6393.

44. Tausendschon M, Dehne N, Brune B: Hypoxia causes epigenetic gene regulation in macrophages by attenuating Jumonji histone demethylase activity. Cytokine 2011, 53:256-262.

45. Sica A, Saccani A, Bottazzi B, Bernasconi S, Allavena P, Gaetano B, Fei F, LaRosa G, Scotton C, Balkwill F, Mantovani A: Defective expression of the monocyte chemotactic protein-1 receptor CCR2 in macrophages associated with human ovarian carcinoma. J Immunol 2000, 164:733-738.

46. Bosco MC, Reffo G, Puppo M, Varesio L: Hypoxia inhibits the expression of the CCR5 chemokine receptor in macrophages. Cell Immunol 2004, 228:1-7.

47. Murdoch C, Lewis CE: Macrophage migration and gene expression in response to tumor hypoxia. Int J Cancer 2005, 117:701-708.

48. Yang MH, Wu KJ: TWIST activation by hypoxia inducible factor-1 (HIF-1). Cell Cycle 2008, 7:2090-2096.

49. Pollard JW: Review of: Overexpression of the colony-stimulating factor (CSF-1) and/or its receptor c-fms in mammary glands of transgenic mice results in hyperplasia and tumor formation. BCO 2005, 8:e10.

50. Scholl SM, Pallud C, Beuvon F, Hacene K, Stanley ER, Rohrschneider L, Tang R, Pouillart P, Lidereau R: Anti-colonystimulating factor-1 antibody staining in primary breast adenocarcinomas correlates with marked inflammatory cell infiltrates and prognosis. J Natl Cancer Inst 1994, 86:120-126.

51. Song MN, Cho SY: CD14 Acts as an angiogenic factor by inducing basic fibroblast growth factor (bFGF). Bull Korean Chem Soc 2007, 28:1613-1614

52. Król M, Pawłowski KM, Majchrzak K, Dolka I, Abramowicz A, Szyszko K, Motyl T: Density of tumor-associated macrophages (TAMs) and expression of their growth factor receptor MCSF-R and CD14 in canine mammary adenocarcinomas of various grade of malignancy and metastasis. Pol J Vet Sci 2011, 14:3-10.

53. Kirma N, Luthra R, Jones J, Liu YG, Nair HB, Mandava U, Tekmal RR: Overexpression of the colony-stimulating factor (CSF-1) and/or its receptor c-fms in mammary glands of transgenic mice results in hyperplasia and tumor formation. Cancer Res 2004, 64:4162-4170.

54. Filderman AE, Bruckner A, Kacinski BM, Deng BM, Remold HG: Macrophage colony-stimulating factor (CSF-1) enhances invasiveness in CSF-1 receptor-positive carcinoma cell lines. Cancer Res 1992, 53:3661-3666.
55. Wrobel CN, Debnath J, Lin E, Beausoleil S, Roussel MF, Brugge JS: Autocrine CSF-1R activation promotes Src-dependent disruption of mammary epithelial architecture. J Cell Biol 2004, 165:263-273.

56. Murdoch C, Giannoudis A, Lewis CE: Mechanisms regulating the recritment of macrophages into hypoxic areas of tumors and other ischemic tissues. Blood 2004, 104:2224-2234.

57. Kaler P, Galea V, Augenlicht L, Klampfer L: Tumor associated macrophages protect colon cancer cells from TRAIL-induced apoptosis through IL-1 $\beta$ dependent stabilization of snail in tumor cells. PLoS One 2010, 5(7): e11700.

58. Rao NA, van Wolferen ME, Gracanin A, Bhatti SF, Król M, Holstege FC, Mol JA: Gene expression profiles of progestin-induced canine mammary hyperplasia and spontaneus mammary tumors. J Physiol Pharmacol 2009, 60:73-84.

doi:10.1186/1746-6148-8-16

Cite this article as: Król et al:: Global gene expression profiles of canine macrophages and canine mammary cancer cells grown as a co-culture in vitro. BMC Veterinary Research 2012 8:16.

\section{Submit your next manuscript to BioMed Central and take full advantage of:}

- Convenient online submission

- Thorough peer review

- No space constraints or color figure charges

- Immediate publication on acceptance

- Inclusion in PubMed, CAS, Scopus and Google Scholar

- Research which is freely available for redistribution

Submit your manuscript at www.biomedcentral.com/submit
C Biomed Central 